San Jose State University

SJSU ScholarWorks

Master's Theses

Master's Theses and Graduate Research

Spring 2011

\title{
African American Community College Student Perceptions of Mathematics Instructor Immediacy Behaviors and Perceived Cognitive Learning
}

Georgia Lynne Toland

San Jose State University

Follow this and additional works at: https://scholarworks.sjsu.edu/etd_theses

\section{Recommended Citation}

Toland, Georgia Lynne, "African American Community College Student Perceptions of Mathematics Instructor Immediacy Behaviors and Perceived Cognitive Learning" (2011). Master's Theses. 3957. DOI: https://doi.org/10.31979/etd.ubaw-cra3

https://scholarworks.sjsu.edu/etd_theses/3957

This Thesis is brought to you for free and open access by the Master's Theses and Graduate Research at SJSU ScholarWorks. It has been accepted for inclusion in Master's Theses by an authorized administrator of SJSU ScholarWorks. For more information, please contact scholarworks@sjsu.edu. 


\title{
AFRICAN AMERICAN COMMUNITY COLLEGE STUDENT PERCEPTIONS OF MATHEMATICS
} INSTRUCTOR IMMEDIACY BEHAVIORS AND PERCEIVED COGNITIVE LEARNING

\author{
A Thesis \\ Presented to \\ The Faculty of the Department of Mathematics
}

San José State University

In Partial Fulfillment

of the Requirements for the Degree

Master of Arts

by

Georgia L. Toland

May 2011 
(C) 2011

Georgia L. Toland

ALL RIGHTS RESERVED 
The Designated Thesis Committee Approves the Thesis Titled

\section{AFRICAN AMERICAN COMMUNITY COLLEGE STUDENT PERCEPTIONS OF MATHEMATICS} INSTRUCTOR IMMEDIACY BEHAVIORS AND PERCEIVED COGNITIVE LEARNING

by

Georgia L. Toland

APPROVED FOR THE DEPARTMENT OF MATHEMATICS

SAN JOSÉ STATE UNIVERSITY

May 2011

Dr. Trisha Bergthold

Dr. Joanne Rossi-Becker

Dr. Steven Millner
Department of Mathematics

Department of Mathematics

Department of African American Studies 


\begin{abstract}
AFRICAN AMERICAN COMMUNITY COLLEGE STUDENT PERCEPTIONS OF MATHEMATICS INSTRUCTOR IMMEDIACY BEHAVIORS AND ASSOCIATED COGNITIVE LEARNING

by Georgia L. Toland
\end{abstract}

The purpose of this research is to examine what instructor immediacy behaviors are perceived to most positively affect the perceived cognitive learning of African American community college mathematics students. Data were provided via voluntary student surveys collected in various mathematics classrooms at two community colleges. The survey instrument was modeled from the works of Gorham (1988) and Sanders and Wiseman (1990) and included an experimental survey method of direct questioning. The perceptions of African American community college students regarding the behaviors of their mathematics instructors, along with their stated preferred instructor behaviors, produced a subset of effective strategies similar to those discussed in prior research that was not specifically related to African American students or mathematics. Results suggest that immediacy is important to the perceived cognitive learning of these students and that further research is required to gain a complete understanding of immediacy and how it manifests in this context. 


\section{Table of Contents}

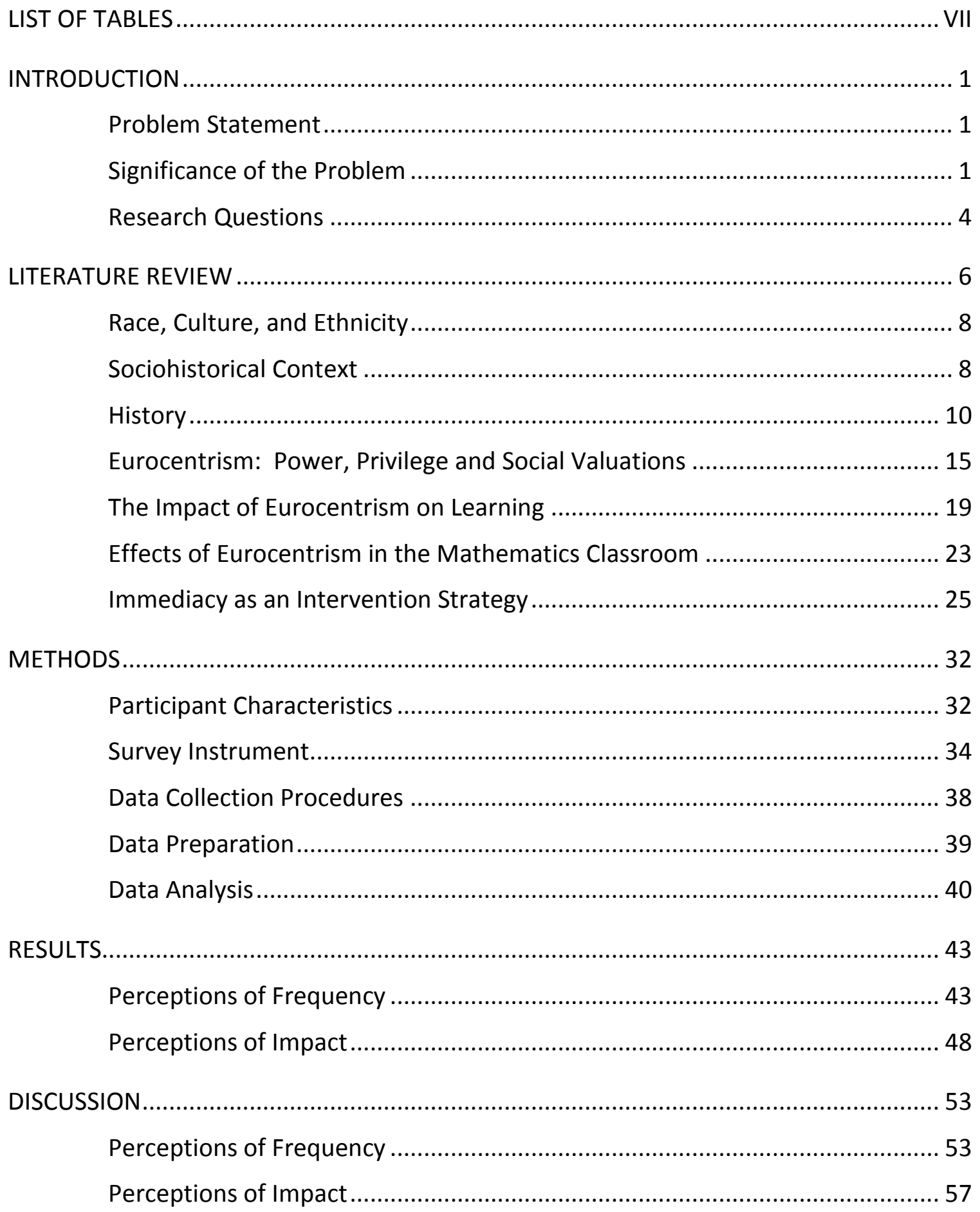




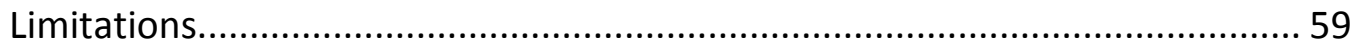

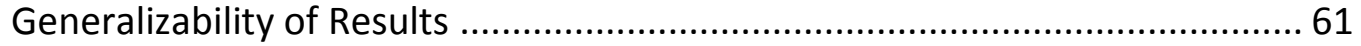

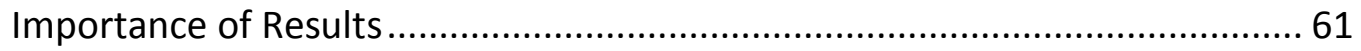

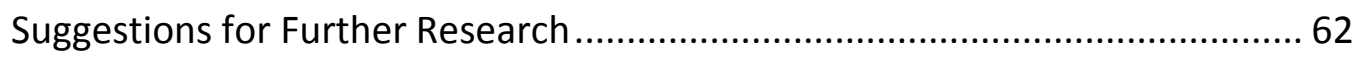

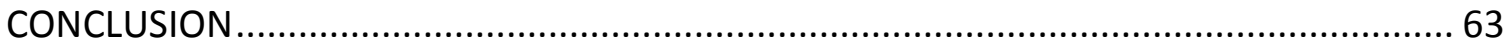

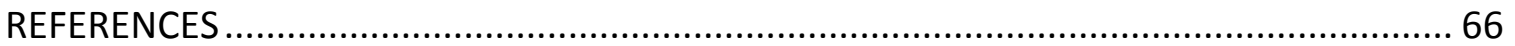

APPENDICES

APPENDIX A: PARTICIPANT DEMOGRAPHICS OF PARTICIPATING COLLEGES .................. 72

APPENDIX B: DEMOGRAPHIC INFORMATION BY MATHEMATICS COURSE ................... 73

APPENDIX C: INSTITUTIONAL REVIEW BOARD APPROVAL OF RESEARCH..................... 74

APPENDIX D: INSTRUCTOR AGREEMENT TO PARTICIPATE IN RESEARCH ..................... 75

APPENDIX E: STUDENT AGREEMENT TO PARTICIPATE IN RESEARCH .......................... 76

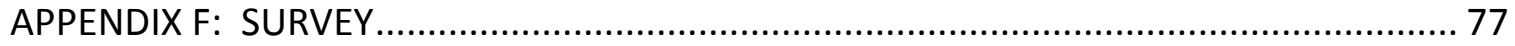

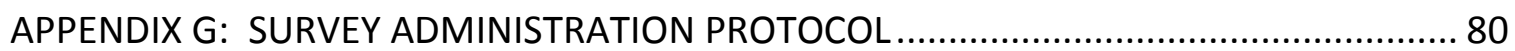

APPENDIX H: DESCRIPTION OF DEMOGRAPHIC CATEGORIES ................................... 82 


\section{List of Tables}

1. Correlation Between Nonverbal Immediacy Behaviors and Perceived Cognitive Learning by Race - Perceptions of Frequency

2. Correlation Between Verbal Immediacy Behaviors and Perceived Cognitive Learning by Race - Perceptions of Frequency

3. Correlation Between Nonverbal Immediacy Behaviors and Perceived Cognitive Learning by Race - Perceptions of Impact

4. Correlation Between Verbal Immediacy Behaviors and Perceived Cognitive Learning by Race - Perceptions of Impact

5. Number of Respondents by Race to the Short Answer Question 50 


\section{Introduction}

\section{Problem Statement}

The problem addressed in this study is to describe the extent to which African American community college students' perceptions of mathematics instructors' immediacy behaviors are associated with their perceived cognitive learning. Immediacy behaviors are those that communicate warmth and closeness (Anderson, 1985) and they have been shown in some settings to affect students' perceived cognitive learning. The focus here is on immediacy behaviors of community college mathematics instructors and how these behaviors are perceived by African American students.

\section{Significance of the Problem}

It is a well known phenomenon, often called the "achievement gap," that African American students are performing well below their White counterparts on tests of academic aptitude in mathematics. The trends in mathematics education show that, although Black students have increased their scores on standardized tests, the gap between White and Black students' scores is still very high and not closing rapidly. For example, according the National Assessment of Educational Progress' testing results for $2009,12^{\text {th }}$ grade African American students score below all other racial groups (U.S. Department of Education, Institute of Education Sciences, National Center for Educational Statistics, 2009). In addition, the gains made by Black students from 2005 to 2009 are equivalent to the gains made by White students (U.S. Department of 
Education, Institute of Education Sciences, National Center for Educational Statistics, 2009). Thus, even as $12^{\text {th }}$ grade Black students raise achievement scores, the gap continues to remain the same. This also suggests that, although not all community college students come directly out of high school, the achievement gap continues even into community college

The disparity in achievement scores has been an issue that has been addressed in a plethora of mathematics education research (see, for example, Ladson-Billings 1995; Martin, 2000; and Tate, 1995) and produced a multitude of conclusions regarding, among other things, curriculum and pedagogy. The concepts of previous research have led to the ideas of ethnomathematics (D'Ambrosio, 1985), culturally relevant pedagogy (Ladson-Billings, 1994), and multicultural education (Banks, 1995) which seek to offer mathematics curricula and learning environments that are more culturally inclusive. Although this study does not seek to discount the importance of these concepts, it will address the issue of educating African American community college mathematics students through a slightly different lens.

Over the past 25 years, a substantial body of research has been conducted on the topic of teacher immediacy and its effects on students' learning. The bulk of this literature and theory does not reflect the increasing diversity being experienced in classroom settings nor does it take into account the subject being taught. Thus, it is legitimate to question the whether the conclusions based on research with predominantly White students in non-mathematics courses can be generalized, or is 
even relevant, to more diverse mathematics contexts. In multicultural studies of university students that do not take into account subject area, it has been shown that teacher immediacy does have a positive, cross-cultural effect on cognitive learning and that certain behaviors may be more effective for different ethnic groups (Sanders \& Wiseman, 1990). However, it may not be reasonable to assume that the same behaviors will be considered to be immediate across subject areas or that behaviors will affect perceived cognitive learning in the same way. The concepts of stereotype threat and receiver apprehension will be discussed as obstacles to the learning of African American community college mathematics students and as possible explanations of why immediacy may affect perceived cognitive learning differently for these students based on sociohistorical factors.

This study will specifically examine how community college instructors communicate, verbally and nonverbally, and how African American community college mathematics students perceive the frequency and impact of these behaviors. The importance here, and a difference from most research in mathematics education, is that this study's interests lie in how instructors are communicating and not what is being communicated. That is, this study seeks not to examine what topics mathematics instructors are teaching or how the topics are being presented in terms of curriculum but how instructor behaviors, regardless of mathematical topic, are perceived by African American community college students. In this case, the premise is that appropriate and effective communication by an instructor precedes anything in the curriculum and, 
because all communication includes affect, communication behaviors are a vital part of any pedagogy. That is, every interaction says something about the interpersonal relationship between instructor and student, so regardless of how well a non-immediate mathematics instructor presents the materials, students, in particular African American community college students, may not learn as much as they would from a mathematics instructor who presented materials in a similar way and utilized immediacy as part of their pedagogy.

\section{Research Questions}

1. Perceived cognitive learning and verbal versus nonverbal immediacy behaviors. Are there differences in African American community college students' perceptions of their mathematics instructor's verbal immediacy behaviors versus nonverbal immediacy behaviors? How are these behaviors associated with students' perceived cognitive learning? In particular, for African American community college mathematics students, are there specific immediacy behaviors that are significantly correlated with their perceived cognitive learning? Overall, for African American community college students, are verbal immediacy behaviors more or less strongly correlated with perceived cognitive learning than are nonverbal immediacy behaviors?

2. Perceived impact of immediacy behaviors. To what extent do African American community college students perceive a teacher's immediacy behaviors as having 
an impact on their learning in a mathematics class?

3. Perceived significance of high-impact immediacy behaviors. For those immediacy behaviors perceived to most dramatically impact African American community college students' learning of mathematics, why are those behaviors so significant in a mathematics class? 


\section{Literature Review}

Dehumanization, although a concrete historical fact, is not a given destiny but the result of an unjust order that engenders violence in the oppressors, which in turn dehumanizes the oppressed. (Friere, 2009, p. 44)

This literature review begins with a broad description of the historical and cultural factors that are the basis for many of the issues African American community college mathematics students face in today's educational system. Specific concepts from the areas of social psychology and communications are examined and applied to the learning of mathematics by African Americans, leading to this study's focus on immediacy behaviors as effective intervention strategies.

The history that will be discussed would be deemed by many as something that most people are aware of. However, it is often argued that mathematics is culture-free or transcends culture and this position denies the race and culture of its students (Bishop, 1988). It is the intention here to make clear, in no uncertain terms, that the sociohistorical context of African Americans is important to the teaching of mathematics and how ignoring or denying the sociohistorical factors is a disservice to African American community college students. As noted by Hecht, Jackson, and Ribeau, "knowledge of a culture is necessary for any consideration of [communication] appropriateness and effectiveness" (2003, p. 94). This includes the communication of knowledge.

After the sociohistorical context, a discussion of Eurocentrism, power, and privilege will be given to provide a contemporary social setting on which to build the 
discussion. Then the topics of stereotype threat and receiver apprehension will be addressed as obstacles that are detrimental to the mathematics learning of African Americans. These two concepts have been taken from the areas of social psychology and communications, respectively.

Finally, immediacy will be discussed as a means of positively influencing African American community college students and their mathematics learning in ways that may overcome stereotype threat and receiver apprehension.

As a mathematics educator reads this, the question may arise as to how these concepts are relevant to mathematics education. As noted by Cobb and Hodge (2002), although there is a considerable amount of research on which mathematics educators can draw, many of the ideas proposed are not specific to the teaching and learning of mathematics. However, that is not to say that these ideas are not potentially relevant to mathematics education, but that they cannot simply be applied without proper study to address and find appropriate ways of adaptation to the concerns and interests of the mathematics education community (Cobb \& Hodge, 2002). In this piece the beginnings of such an adaptation are presented; the concepts of stereotype threat, receiver apprehension, and immediacy from the areas of communications and social psychology are connected, not only to mathematics education, but specifically the mathematics education of African American community college students. 


\section{Race, Culture, and Ethnicity}

Before diving into the previous research, the question of race, culture, and ethnicity should be addressed. In this study, ethnicity and race are considered as two parts of the same concept. Race is a social construction and it is contended that the racial identities people develop are related to their participation in the practices of a particular community which molds their culture and identity (i.e. ethnicity) (Nasir, 2002). Thus, race and ethnicity are considered to be dynamically interrelated and, for the purposes of this study, will be used interchangeably.

It is also understood that by choosing to interrelate these concepts, it is easier to generate and test explanations because it is assumed that each ethnic group is homogeneous. It is acknowledged that this practice contributes to the issue of stereotyping, describing student characteristics based on group membership, and treating them based on that description (Cobb \& Hodge, 2002). However, since this type of research is relatively new, it is a starting point which has been deemed an acceptable compromise that should receive more scrutiny as more research is conducted on these topics.

\section{Sociohistorical Context}

Humans are sociohistorical beings.

"Because - in contrast to animals - people can tri-dimensionalize time into the past, the present, and the future, their history, in function of their own creations, develops as a constant process of transformation within...epochal units ... [that] interrelate in the dynamics of historical continuity." (Friere, 2009, 
p. 101)

The continuity of history and the dynamic interrelation between the past, the present, and the future guarantees that history directly affects the present and, in the turn, the present affects the future. In the present, it is often that educators speak and are not understood because they are not attuned to the situation of the students they are addressing (Friere, 2009). To begin to alleviate this, as educators we must humanize our students, and in particular, as it applies to this research, our African American students, by understanding their history from a standpoint that embraces the dynamic interrelation of the three dimensions and does so in a way that does not reduce African American people to things that cannot be related to.

One of the intentions of the study that follows is to offer context to the struggle of African Americans in mathematics education, but this issue cannot be discussed apart from African American sociohistorical and educational experiences within society at large (Martin, 2000). Here it is important that teachers understand their students' lives beyond the classroom and school in order to fully understand their present and directly affect their future (Ladson-Billings, 1995); to "apprehend these themes and to understand...both the people who embody them and the reality to which they refer" (Friere, 2009, p. 107). 


\section{History}

For the purposes of this discussion, a very brief discussion of the historical conditions of African Americans in the United States will be presented as context for the place in the American social strata that African Americans hold.

Colonization and chattel slavery. Since its beginnings, the European colonization of the North American continent has involved the subordination of people of color, beginning with the indigenous peoples of the land (Feagin \& Feagin, 2003). The European colonists actively participated in the murder of indigenous peoples and the theft of their lands and justified these trespasses as driving the "savages" off of valuable land (Feagin \& Feagin, 2003). This type of injustice against the indigenous people was just the first of a long lineage of injustices to come.

With one of the first settlements, Jamestown, located in what is now Virginia, came the importation of the first Africans and the beginnings of the institution of chattel $^{1}$ slavery (Feagin \& Feagin, 2003). By the mid-1600s the slave status of Africans had been completely institutionalized in colonial law and by 1700 African slaves were officially designated as chattel (Feagin \& Feagin, 2003). For the next 200 years virtually every African that was imported into America was sold into involuntary servitude, thus

\footnotetext{
${ }^{1}$ Chattel references personal property and is derived from the word cattle (Chattel, n.d.). That is, slaves were the property of their masters, just as livestock, and could be bought and sold accordingly. Additionally, this lifetime bondage was hereditary so children of slaves were also slaves and, as their parents, could be bought and sold away from their families.
} 
facilitating the expansion of the agricultural industry and the wealth of White America.

The question then becomes, how was this brutal and immoral practice of chattel slavery able to continue for over 200 years? To answer this question, we must first examine how chattel slavery became racialized, or put differently, how African became synonymous with slave.

Racialization of slavery. Between 1668 and 1723, a series of laws were passed in Virginia. Their purpose was to "not only impose lifetime hereditary bond-servitude on African Americans, but to implement it by a system of racial oppression, expressed in laws against free African Americans" (Baum, 2006, p. 47). This idea of the racialization of slavery became accepted throughout the new colonies and created the de facto invention of a superior White race. That is, whiteness became the "characteristic, the attribute, the property of free human beings" and this privilege was built on the exclusion and racial subjugation of Africans (Harris, 1993, p. 1721).

African Americans were not only legally excluded from freedom but from education, as well. Even 150 years later in 1865, after the Civil War when slaves were supposedly free, legalized segregation continued the enslavement by placing strict limits on "freedom." Most public facilities, including schools, were segregated throughout the country, not just in the South as history books would have us believe. African Americans had to find ways to fund their own schools as public funding was segregated as well and a government that condoned segregation clearly did not spend as much on Black students as it did on Whites. 
Struggle for social equality. It would not be until the mid-1900s that African Americans would begin to gain legal advancement toward equality with the Civil Rights Act of 1964 and the Voting Rights Act of 1965 which, under the law, ended racial segregation in public accommodations and discriminatory voting practices (e.g. literacy tests). The italics are added to note that African Americans are still struggling for social equality.

Four hundred years of oppression cannot be undone when the culture that wields the power is unwilling to relinquish that power to create a truly equitable social situation. It should be noted that, because African Americans have been oppressed since their introduction into the United States, they have acculturated ${ }^{2}$ to the extent necessary for survival within the structure of domination. However, because it seems unchangeable to some African Americans, they have resigned themselves to the lower social status that has been assigned to them by the White privileged class.

"So often do [African Americans] hear that they are good for nothing, know nothing, and are incapable of learning anything - that they are sick, lazy, and unproductive-that in the end they become convinced of their own unfitness" (Friere, 2009, p. 63). A very public reminder of the attempt to convince America of its unfitness came in the early 1970s with the Eugenics Movement in America.

Eugenics. Eugenics is a science that deals with the improvement of hereditary

\footnotetext{
${ }^{2}$ Acculturation is defined as "cultural modification of an individual, group, or people by adapting to or borrowing traits from another culture" (Acculturation, n.d.).
} 
characteristics of a race or breed and is generally used in reference to humans (Eugenics, in Merriam-Webster Online Dictionary (11th Ed.), n.d.; Eugenics, in Brittanica Online Encyclopedia, n.d.). The term was first used in 1883 by Sir Francis Galton as a way to extend his cousin Charles Darwin's theory of natural selection to humans (Bashford \& Levine, 2010). The core of the logic of eugenics is that some human life is more valuable to society than other human life and that the human race can be genetically improved by selective mating or other means (Bashford \& Levine, 2010; Wikler, 1999). Eugenicists tended to believe that the human species could be improved if families with more "favorable" genetic traits increased their rate of procreation while discouraging procreation by families with less favorable genetic characteristics (Wikler, 1999).

In the 1970s, a Nobel Prize winning physicist turned eugenicist named Dr. William Shockley became highly publicized for his work in the field of eugenics. His work was funded by racist organizations and, although Shockley did not appear to be a traditional racist due to his scientific explanations of his theories, he appeared to the White-American public as the bringer of scientific "proof" that Blacks are intellectually inferior to Whites. Shockley's work led him to the conclusion that, not only were Blacks less intelligent than Whites, but that the Black population would become less intelligent over time because unskilled (rural) Blacks had more children than skilled (non-rural) Blacks (Dr. Welsing \& Shockley [sic] Debate Pt 4, 1974). This, he suggested, showed that the least effective elements of society (mostly Black) were reproducing at a more rapid 
rate, triggering the downfall of the race. In all fairness, Shockley also believed this to be true for Whites but that the effect was not as critical because the least effective Whites were not reproducing as fast as the least effective Blacks. He also suggested, via a thinking exercise, that regardless of race, people with an IQ below 100 be paid to undergo voluntary sterilization (Shockley, 1972, p. 306). This idea would not be intentionally directed toward Blacks but, based on Shockley's IQ test results, would affect far more Blacks than Whites.

William Shockley is a representation of the view that a number of White Americans had regarding the inferiority of Blacks. The fact that his ideas, and the ideas of those like him, were popular and distributed to assist in discrimination against Blacks reveals that the climate of US society was hostile toward the idea of integration. Even after the Brown decision, the Civil Rights Act, and the Voting Rights Act, mainstream America was not yet ready to accept Black citizens as equals.

Thus, the history of African Americans in the United States, even within the last 40 years, is one of oppression, differential treatment, and denied opportunity. It is this legacy that continues to plague African Americans in contemporary society, particularly within the education system. As educators, it is important that we realize this and know that this legacy, and the nuances within the African American culture that it has created, are crucial in actualizing how we interact with African American students. Without this information as a foundation, it is difficult to build a successful communication strategy because the starting point is unclear. Therefore it is necessary to understand, not only 
the history, but the contemporary outcomes of past events that now shape how American society is structured by power and privilege.

\section{Eurocentrism: Power, Privilege and Social Valuations}

Most white people prefer not to perceive their nation and its major institutions as 'white', and consequently racist. They will say that the United States is a multiracial society, and becomes more so every day. The same strictures, they will add, hold for its major organizations and associations...Black Americans seldom see the reality this way. (Hacker, 1992, p. 22)

The brief history provided in the section above sets the stage for exploring how the sociohistorical context of African Americans shapes contemporary society and how the legal power and privilege structure that was put into place continues to affect African Americans. Through examining this historical legacy of denied opportunity in American society, a direct parallel to denied opportunity in mathematics education is evident. This further directs much needed attention to how African Americans have responded and adapted to this historical legacy (Martin, 2000; Tate, 1995).

To begin with, it is important to briefly define the concept of Eurocentrism, as it helps to lay a foundation to understanding the historical context. Eurocentrism is defined as the "tendency to interpret the world in terms of western and especially European or Anglo-American values and experiences" (Eurocentrism, n.d.). In addition, Eurocentrism is the justification of inequity and exploitation through the [tacit] acceptance of the dominant White norms and privileges as given (King, 1991). Inherent in this concept is the belief that whiteness is better and has a higher value than 
blackness. The value of whiteness came in many forms, the most important of which was that whiteness was the prerequisite for freedom and freedom was the prerequisite for everything else. So freedom, and hence power, was a privilege; not an earned privilege, but one granted to those with a specific physical attribute by those with the same attribute. This means all of the possible outcomes of freedom and power were also privileges, albeit privileges available only to White people. Regardless of the advancements toward racial equality, it should be clear that this system of White privilege, although manifested differently, is still in place. For example, Oakes, Ormseth, Bell, and Camp (1990) found that as a school's African American enrollment increases, the proportion of "high ability" classes diminishes and that schools with higher concentrations of African American students have fewer teachers judged to be highly qualified in mathematics. Thus, it would appear that America does not value the education of African Americans as much as Whites. This is only one example of many that illustrates that being White in today's society still has a value that is higher than that of being non-White, in particular, Black.

This discussion leads us to the question, how much is it worth to be White instead of Black? Andrew Hacker in his book Two Nations (1992) posed this question in the form of a parable, to his predominantly White college class. The parable was as follows:

You will be visited tonight by an official you have never met. He begins by telling you that he is extremely embarrassed. The organization he represents has made a mistake, something that hardly ever happens. 
According to their records, he goes on, you were to have been born black: to another set of parents, far from where you were raised.

However, the rules being what they are, this error must be rectified as soon as possible. So at midnight tonight, you will become black. And this will mean not simply darker skin, but the bodily and facial features associated with African ancestry. However, inside you will be the person you always were. Your knowledge and ideas will remain intact. But outwardly you will not be recognizable to anyone you now know.

Your visitor emphasizes that being born to the wrong parents was in no way your fault. Consequently, his organization is prepared to offer you some reasonable recompense. Would you, he asks, care to name a sum of money you might consider appropriate? He adds that his group is by no means poor. It can be quite generous when the circumstances warrant, as they seem to in your case. He finished by saying that their records show you are scheduled to live another fifty years-as a black man or woman in America.

How much financial recompense would you request? (Hacker, 1992, pp.

Hacker found that most of his White students felt that fifty million dollars, or one million dollars for every year of being Black, was a reasonable amount to ask (Hacker, 1992).

Although Hacker's exercise was not performed in a research setting, it is a testimony to the existence of the covert hierarchy that is placed on skin color in American society. It is difficult to believe that equality, in any sense of the word, is attainable when African Americans are considered to have less value than White Americans. This was exemplified in Daniel Bernard Martin's interview-based, mathematics education research with African American adults. Martin (2007) found that two of the main issues confronting Blacks as mathematics learners are racial boundaries and "perceived position and devalued social status" (p. 148). He argues that “life experiences as an African American, often characterized by struggle and social devaluation, make it difficult to maintain a positive identity in the pursuit of 
mathematics knowledge" (p. 157). Without a positive identity as learners of mathematics, African Americans will continue to struggle in this realm. However, the question to be asked is how do we begin to create this positive identity for African American students when society's message is quite the contrary? The study that follows hopes to begin to answer this very question.

Since the time that the United States was colonized by the Europeans, Africans in America have had to face unique challenges. Starting with being forcibly removed from their native land and turned into chattel slaves, African Americans have had to overcome many obstacles both legally and systemically, through the laws that have been put into place forbidding them from moving up the social ladder. While times have changed, many of these sociohistorical obstacles are still apparent in the systems that exist today, and do affect African Americans as individuals and, hence, as students of mathematics. For example, according to the US Census Bureau for the year 2000, 25\% of African Americans lived below the poverty level, $7 \%$ were unemployed, and $43.5 \%$ had an annual income less than $\$ 25,000$ as compared with $9 \%, 3 \%$, and $26 \%$ respectively for White Americans (U.S. Census Bureau, 2000) ${ }^{3}$. This illustrates the outcome of the discrimination of the past which has hindered ability of African Americans to build wealth. Further, it illustrates that a large portion of African Americans have concerns about meeting their basic needs such as food and shelter as

${ }^{3}$ Census data for 2010 was not available prior to completion of this project. 
well as their needs in terms of health and safety. This means that often African American students are focused on fulfilling their basic needs and education falls to the wayside perpetuating the inability to create wealth and social mobility. This is one of many ways in which Eurocentrism, either directly or indirectly, impacts the education of African American students at all levels.

\section{The Impact of Eurocentrism on Learning}

African American community college students are being educated within a system that is based on a Eurocentric societal construct (white privilege) that creates a hierarchy that places them at the bottom. This hierarchy extends into the classroom creating an invisible threat, known as stereotype threat, which causes students to disidentify with mathematics. Stereotype threat may also cause receiver apprehension which leads to students having fears about being able to properly decipher the psychological messages being sent by their instructors in classroom interactions. Each of these phenomena poses a challenge to African American community college students in the mathematics classroom.

\section{Stereotype threat and disidentification}

What every black American knows, and whites should try to imagine, is how it feels to have an unfavorable-and unfair-identity imposed on your every waking day. (Hacker, 1992, p. 21)

Throughout American history, Blacks have been stereotyped as lazy, unintelligent, and uncivilized and these ideas continue in contemporary times. The 
social stereotype of the intellectual inferiority of African Americans in mathematics has been "proven" by the results of standardized national achievement examinations (e.g. the National Assessment of Educational Progress). Thus, within this domain, and in the educational domain overall, African Americans are constantly faced with the pressure of disproving these stereotypes. This "social-psychological threat that... threatens one with being negatively stereotyped, with being judged or treated stereotypically, or with the prospect of conforming to [some negative] stereotype" is referred to as stereotype thre (Steele, 1997, p. 614; Steele \& Aronson, 1995) at. In numerous studies with university students, this threat has proven that it can undermine the intellectual performance of African Americans, even those who are high achieving and identify ${ }^{4}$ with the field of mathematics (Steele \& Aronson, 1995; Steele, 1999; Steele, 1997). Further, when the threat is chronic, as in African Americans who spend considerable time in a competitive, White male oriented math environment ${ }^{5}$, it can cause disidentification whereby the effected student retreats from the threat by not associating mathematics as relevant to his or her self-definition (Steele, 1997, p. 614). Thus, in many cases,

\footnotetext{
${ }^{4}$ Identify: psychological orientation of the self in regard to something (as a person or group) with a resulting feeling of close emotional association (Identify, n.d.). ${ }^{5}$ College mathematics environments are, more often than not, dominated by White students as is shown by the number of bachelor's degrees in math or statistics awarded in the 2006-2007 school year. White students made up 73.3\% of the degrees while Black students received 5.7\% of the degrees (U.S. Department of Education, 2008). Many would argue that there are disproportionately less Black people in the general population but Blacks make up approximately $13 \%$ of the US population so $5.7 \%$ is significantly lower than what might be expected based on population statistics (U.S. Census Bureau, 2000).
} 
stereotype threat causes African American university students to disidentify with mathematics and leads to the diminishing of affective learning ${ }^{6}$ and hence cognitive learning.

The prevalence of these inferiority stereotypes in society makes it plausible that African American community college students may worry that other students, as well as adults, in the mathematics environment will doubt their abilities. It is also plausible that students who do not perform well may take on these doubts as their own and begin to identify with them. This can influence a student's performance and, if the doubt is not addressed, may lead to the student disidentifying with mathematics. There are certain strategies that have been found to ease this worry (stereotype threat) and prevent disidentification. One such strategy is for teachers to create a potential-affirming relationship with the student (Steele, 1997, p. 624). One step to creating such relationships is that teachers must adopt a communication structure that creates a positive student-teacher relationship that emphasizes the potential of the student to excel. For example, Steele's experiments with essay writing showed that when African American university students were given critical feedback in a manner that explicitly stated the instructor's belief that the student could meet the high standards being required, they were the most motivated of any of the groups in the study (Steele, 1999).

\footnotetext{
${ }^{6}$ Affective learning (in mathematics education) is concerned with students' attitudes, beliefs, and values and occurs when students develop an appreciation and value of mathematics education (Mottet, Garza, Beebe, Jurrells, \& Furler, 2008).
} 
Although this study was not in the field of mathematics, it suggests that teacher communication strategies with the student can be a critical tool for motivating African American students and increasing affective learning by decreasing disidentification (Mottet, Garza, Beebe, Houser, Jurrells, \& Furler, 2008).

Receiver apprehension. Receiver apprehension was conceptualized by Dr. Lawrence R. Wheeless (1975, p. 268), professor of communication studies, as "the fear of misinterpreting, inadequately processing, and/or not being able to adjust psychologically to messages sent by others". This behavior has been shown to detrimentally affect the performance of students in the classroom. Listening effectiveness, achievement scores, perceived cognitive learning, motivation to learn, and short and long term recall of information have all been shown to be negatively affected by receiver apprehension (Preiss, Wheeless, \& Allen, 1990; Daniels \& Whitman, 1979; Roberts, 1986; Scott \& Wheeless, 1975; Chesebro \& McCroskey, 2001).

It appears that stereotype threat and receiver apprehension may be closely related. The causes of receiver apprehension include social evaluation and listener motivation (Ayres, Wilcox, \& Ayres, 1995). Students that were motivated to listen based on the necessity to recall the information in the future, for classroom activities like instructional evaluation, have been found to experience receiver apprehension more often than students that were not motivated in this way (Ayres, Wilcox, \& Ayres, 1995). Consider, for example, an African American student who identifies with mathematics. This student may experience stereotype threat and have the fear that he or she may 
conform to an inferiority stereotype such as "Blacks do not do well in math". To try to alleviate stereotype threat, the student would be motivated to do well on tests and obtain good grades. In this case the African American student would be experiencing a potential social evaluation (stereotype threat) and an evaluation based on recall where both of these are causes of receiver apprehension.

It has been shown that teacher clarity and immediacy help reduce, and largely overcome, receiver apprehension in the instructional context (Chesebro \& McCroskey, 2001; Ellis, 2004). Again, these studies did not address African Americans or mathematics but it is likely that their conclusions could be adapted and extend to these realms.

\section{Effects of Eurocentrism in the Mathematics Classroom}

Eurocentrism, as a societal construct, effects every part of society including educational institutions, in particular, classroom dynamics and curriculum, in ways that can be detrimental to the learning of African American students.

Classroom dynamics. For this section mathematics education is considered as a subculture of the culture of Western (Eurocentric) education. As such, non-White students entering the mathematics classroom are crossing "cultural borders" into the culture of power and often confront "a powerful hidden curriculum that reveals sociocultural factors, including social norms [and] roles...that may infiltrate the subconscious of minority students, resulting in the development of inferior perceptions 
of themselves and their heritage" (Brand, Glasson, \& Green, 2006, p. 229). This crossing immerses the non-White student in the culture of power, the Western mathematics education subculture, within which the student is an outsider (Brand, Glasson, \& Green, 2006). This cultural separation stratifies the mathematics classroom into White students who find it normative to work within the established Eurocentric mathematics subculture and non-White students who are "unsure about their ability to be successful due to their lack of identity with...[this] subculture" (Brand, Glasson, \& Green, 2006, p. 229). This is likely one of the factors that causes the mathematics achievement gap between White and students of color.

Curriculum. Eurocentrism in the mathematics curriculum is directly traced to

Eurocentrism in the history of mathematics.

The standard treatment of the history of non-European mathematics exhibit[s] a deep-rooted historiographic bias in the selection and interpretation of fact, and that mathematical activity outside of Europe had as a consequence been ignored, devalued, or distorted...The contributions of [those the Europeans] colonized were ignored or devalued as part of the rationale for subjugation and dominance. And the developments in mathematics before the Greeks - notably in Egypt and Mesopotamia - suffered a similar fate, dismissed as unimportant to the later history of the subject...The respect for ancient Egyptian science and civilization, shared by ancient Greece and pre-nineteenth century Europe alike, was gradually eroded, leading eventually to the Eurocentric model with Greece as the source and Europe as the inheritor and guardian of the Greek heritage. (Joseph, 1997, pp. 63-64).

Thus the mathematics of the Egyptians, Mesopotamians (also known as Babylonians), Arabs, Indians, and Chinese has been ignored, particularly in education, since the 
nineteenth century (Joseph, 1997) leaving non-White students with a subject whose history does not include them.

Because this status quo has been in place for so long, there are few role models of color in mathematics and, when one is found, they are perceived as an exception to rule (Brand, Glasson, \& Green, 2006). Mathematics is not generally perceived by minority students as a field for minorities due to this lack of role models. If it were perceived to be a field for, say, Black students, the following story told by a Black tutor about an experience with one of his young Black students would be taken as an anomaly:

I remember talking to him at one time, and explained to him that he can do the math. I got to the point where I said, "Let me tell you, there's Black people who have the ability to do this. Black people are intelligent people. You are a young Black boy. You should be able to handle this." And he looked up at me and said, "If Black people are so good at math, if Black people are so smart in everything, how come they don't do so well in math? How come you don't see many of them doing math?" (Martin, 2006, p. 219)

Instead, due in part to Eurocentrism, this is likely the norm and the quote by this third grader is a question that one stumbles to answer without addressing the truths behind the questions. This third grader has already begun to disidentify with mathematics and, in this author's opinion, this is due to the factors discussed above.

\section{Immediacy as an Intervention Strategy}

The quote by the third grader above illustrates the need for interventions at all 
educational levels. Communication is important since, as educators, our ultimate goal is to effectively communicate information with the desired outcome of cognitive learning. The first step to effective communication is an understanding of what communication is, how it works, and what strategies can be used to better facilitate learning.

Communication. To communicate is to "transmit information, thought, or feeling so that it is satisfactorily received or understood" (Communicate, n.d.). Every human interaction involves communication of some sort, be it verbal or nonverbal, and each of these forms of communication requires the receiver to interpret and react to the information being communicated. How the communicator chooses to transmit information signals to the receiver to either approach or avoid which, in turn, affects how the receiver will react to the intended communication. With this in mind, it is clear that how a communicator chooses to transmit information is crucial to producing a particular response and that the particular response to the same transmission may vary depending upon the receiver.

Immediacy. Emotion is central to all human interaction and influences all human behavior (Mottet \& Beebe, 2002). Thus, it should be recognized that all interactions between teachers and students include affect and these interactions are subconsciously evaluated largely through interpretation of communication cues (Richmond, Gorham, \& McCroskey, 1987).

According to Mehrabian, a psychologist, immediacy refers to the degree of 
perceived physical or psychological closeness between communicators (Mehrabian, 1969). Immediacy behaviors signal availability for communication, increase sensory stimulation, and communicate warmth and closeness (Anderson, 1985). According to Anderson (1985), the process of communicating this warmth or intimacy to one another is the most important aspect of communication because there is no affectively neutral communication and every interaction says something about our interpersonal relationships.

There has been much research since the late 1970s addressing the topic of teacher communication and its effects on the affective and cognitive learning of students in the fields of communications and other liberal arts. Even in early research it was shown that there is a strong association between teacher immediacy and affective learning (Andersen, 1979). For teachers of mathematics, or any other subject for that matter, the idea is to create an approach response from students; that is, to utilize a communication structure that includes immediacy behaviors. Immediacy is an important part of effective communication and effective communication is the cornerstone of any good instructional strategy. Communication behaviors play a strategic role in student learning outcomes (Witt \& Wheeless, 2001) and research has shown that teacher communication, both verbal and nonverbal, enhances cognitive and affective learning of students (Gorham, 1988; Kelley \& Gorham, 1988; Mottet \& Beebe, 2002; Plax, Kearney, McCroskey, \& Richmond, 1986; Richmond, Gorham, \& McCroskey, 1987; Sanders \& Wiseman, 1990). Again, none of the sampled studies focused on 
mathematics or African Americans.

In the case of African American mathematics students additional psychological obstacles, as discussed above, must be taken into consideration when discussing effective verbal and nonverbal communication strategies. Additionally, further research is required to determine what teacher immediacy behaviors may help instructors to overcome these obstacles.

Verbal immediacy. Immediacy behaviors can be verbal or nonverbal. However, there has been some discrepancy as to how verbal immediacy is referred to by authors in different fields. Mehrabian defines verbal immediacy as "the degrees of directness and intensity of interaction between communicator and referent in a communicator's linguistic message" (1966, p. 28). For example, in comparing "These people need help" versus "Those people need help," in the first statement the pronoun reflects a closer distance (Mottet \& Richmond, 1997). But evidence suggests that these verbal nuances are virtually undetectable to an untrained ear (Mottet \& Patterson, 1996; Gorham, 1988). Thus it is presumed that, for the purposes of this study, verbal immediacy defined in this way is not a factor that produces a significant effect on the cognitive learning of African American mathematics students. However, in educational research, verbal immediacy has also been used synonymously with verbal behaviors or strategies such as using humor, encouraging students to talk, and praising student work (Gorham, 1988). For the purposes of this study, this is the definition that will be used.

With this in mind, there have been few studies that specifically examine verbal 
immediacy behaviors. However, in a study performed with university students, Gorham (1988), found that both verbal and nonverbal immediacy are positively related to perceived cognitive learning. In particular, the verbal cues that were positively related to perceived cognitive learning include: (a) use of humor, (b) praise of student work, (c) willingness to engage in conversations with students outside of class, (d) self-disclosure, (e) asking questions and encouraging students to talk, (f) asking for student input on assignments, and (g) praise of student work (Gorham, 1988). Sanders and Wiseman (1990) took this study a step further and found that, in a sample of almost 1000 volunteer university students, across ethnic groups, (a), (b), (c), and (e) were positively associated with cognitive learning, showing that many of the same verbal immediacy behaviors were found to positively affect cognitive learning across groups.

Nonverbal immediacy. Most of the research in the realm of immediacy has been done with regard to teacher nonverbal immediacy. In her seminal research, Andersen (1979) identified the following nonverbal cues as being immediate: eye contact, gestures, relaxed body position, directing body position toward students, smiling, vocal expressiveness, movement, and proximity. There have been multiple studies in the shadow of this seminal piece that indicate nonverbal immediacy increases affective learning (Chesebro \& McCroskey, 2001; Gorham, 1988; Mottet \& Beebe, 2002; Plax, Kearney, McCroskey, \& Richmond, 1986). It has also been shown to positively influence perceptions of the teacher and course content, as well as short term recall (Powell \& Harville, 1990). 
While these studies have demonstrated the link between nonverbal immediacy and affective learning, there are few studies that have convincingly demonstrated the same connection between nonverbal immediacy and cognitive learning. Furthermore, few studies have been done specifically addressing this concept taking into account the ethnicity of the participants and none have been found that specifically address mathematics.

Until recently, there was little or no evidence to support that immediacy had any significant effects on cognitive learning. Recent research has shown that nonverbal communication behaviors may induce emotional responses in students that cause the students to feel more connected to the teacher and course which results in increased cognitive learning and greater recall (Mottet \& Beebe, 2002; Witt \& Wheeless, 2001). Utilizing prior research on communication that produces positive learning outcomes in the classroom, Sanders and Wiseman (1990) have shown that different immediacy behaviors are more or less effective across ethnic groups. More specifically, through the use of university student perceptions as measurement based on arguments made by Richmond, Gorham, and McCroskey (1987), Sanders and Wiseman (1990) found that for African American university students maintaining appropriate eye contact, open and relaxed body position, smiling, movement about the room, and physical expressiveness (gestures) positively influence both cognitive and affective learning. In general, research shows that when instructors decreased physical distance between themselves and the student there was a positive correlation with cognitive and affective learning but this 
was not the case with African American students (Sanders \& Wiseman, 1990). This study suggests that, in general, all of the immediate behaviors included had either a positive or neutral correlation with perceived cognitive learning across ethnicities with the exception of close physical proximity of instructors to African American students which had a negative correlation. Thus, regardless of race, immediacy is a strategy that should be employed by community college mathematics instructors to help increase the cognitive learning of their students.

Although there are many sociohistorical factors that have created challenges to learning mathematics for African American community college students, there are ways in which mathematics educators can intervene to help these students succeed. Immediacy behaviors can be incorporated into instructors' communication strategies and can help to alleviate stereotype threat and receiver apprehension thereby reducing instances of disidentification. Based on previous research (e.g., Sanders and Wiseman, 1990), these methods increase the cognitive learning of African American students.

Although none of the cited research in immediacy specifically incorporated mathematics, there is a relationship between communication and learning that is very clear. The study that follows will examine instructor immediacy in relationship to mathematics and African American community college students. 


\section{Methods}

To address the research questions, various methods used in previous research shall be compiled and adapted to determine the verbal and nonverbal behaviors that most positively affect the perceived cognitive learning of African American community college mathematics students. In addition, participant short answer responses shall be used, along with previous research, to determine what it is about these behaviors that create this positive perception.

\section{Participant Characteristics}

The subjects who participated in this study were community college students over the age of 18 , who were enrolled in a mathematics class during the data collection period, March 2010.

Selection of community colleges. Four community colleges in the San Francisco Bay Area were approached to participate in the study. Each had posted population demographics showing an African American student population of approximately $15 \%$ or greater based on enrollment statistics from the Fall 2008 reported by the National Center of Educational Statistics (NCES) (U.S. Department of Education, Institute of Education Sciences, National Center for Educational Statistics, 2009-2010). Two of the four colleges agreed to participate and they are henceforth referred to as College 1 and College 2. See Appendix A for a summary of the racial profiles of the student body of both participating colleges. 
Selection of mathematics classes. For this study, it was desired to obtain information from students from a diverse cross section of mathematics classes. At each institution, all of the instructors in the mathematics department were contacted via email to request their participation in the study. Those instructors that chose to participate provided their class schedules and the researcher created a survey schedule that included as many classes as possible during the research period the campus. Twenty-four classes were surveyed including the following subjects: arithmetic, prealgebra, elementary algebra, intermediate algebra, trigonometry, geometry, discrete mathematics, statistics, and calculus (see Appendix B).

Selection of participants. A total of 574 students from two community colleges volunteered to participate in the study and 529 of the surveys were used for analysis. ${ }^{7}$ The demographic characteristics of the sample are provided in Appendix A.

Protection of human subjects. The use of human subjects in this research was approved by San Jose State University's Institutional Review Board (see Appendix C).

To protect their confidentiality, instructors and participants are not identified in the data collection materials or in the reporting of the findings. Each class was assigned a hyphenated code that indicated the school campus, the type of mathematics class,

\footnotetext{
${ }^{7}$ Forty-five surveys were discarded for at least one of the following reasons: multiple skipped questions, all questions answered the same using a single circle indicating that each question was not read and responded to individually, response to short answer suggested misunderstanding, or subject was a community college student under the age of 18 so information could not be used due to lack of parental consent.
} 
and the date and time of the survey. All raw data, refined data, and data summaries were identified only by the assigned number. All reporting employs pseudonyms, as required, for any individuals.

Only the researcher had access to the materials collected for this study. All printed materials were stored in a locked personal file cabinet which could only be accessed by the researcher and all computer-generated and/or scanned materials were stored in a single password protected file on the researcher's personal computer. Instructors and student participants in this study were volunteers. Each participant was informed about the time required to participate and that this loss of time would be minimal. In addition, each participant was assured that there would be no penalty for refusal to participate or for early withdrawal (see Appendices D and E for consent forms).

\section{Survey Instrument}

The survey is divided into three parts. The first part of the survey, Perceptions of Frequency, asked the subjects to rate how often their current mathematics teacher displayed certain verbal and nonverbal communication behaviors. The second part of the survey, Perceptions of Impact, asked the subjects to imagine their ideal math teacher and rate the impact of these same behaviors to cognitive learning. This section also includes an open-ended, short answer question. The final portion, Demographics, is a demographics questionnaire. Details of each part are discussed below. The survey 
was constructed in this way because the methods of the first portion follow directly from previous research while the methods of the second portion attempt to provide additional data via experimental method of direct questioning.

In Perceptions of Frequency the subjects were questioned about their current mathematics instructor; beyond giving information about behaviors and cognitive learning, this approach offers a current, real life, situation in which subjects can think about the behaviors in action. Then, in Perceptions of Impact, subjects are asked to imagine their ideal teacher and, it was hoped that via Perceptions of Frequency, they would quickly formulate an idea of how their ideal teacher might behave. In this way, Perceptions of Frequency was not only informative on its own, but would also act as a vehicle to prompt subjects to think about the behaviors in question and set the stage to increase the validity of their responses. The Demographics section is placed last so that subjects' were not thinking about the relativity of the answers to the demographics information during the other two parts of the survey. The idea here is to alleviate any stereotype threat that could possibly be experienced during the survey if the demographics questions were to be asked first.

Perceptions of frequency. This portion of the survey has been modeled after previous research (Richmond, Gorham, \& McCroskey, 1987; Sanders \& Wiseman, 1990). Here, subjects were asked to consider their current mathematics teacher and rate the frequency of a series of behaviors on a 5-point scale ranging from never (scored 0), to very often (scored 4). According to Andersen (1979), the use of student reports of 
teacher immediacy behaviors was found to be a valid method for obtaining data as she found a high correlation between the reports of students and the reports of trained observers. Two immediacy behaviors have been selected from the immediacy behaviors studied by Richmond, Gorham, and McCroskey (1987) in their study of immediacy behaviors and cognitive learning and 18 items were adapted from the 22 immediacy behaviors that were studied by Sanders and Wiseman (1990) in a multicultural study of classroom immediacy that built on the Richmond et. al. study. However, since a subset of 20 behaviors has been sampled from two different studies, it should be noted that the inter-item correlation for these 20 items is also quite high (Cronbach's alpha $\left.{ }^{8}=0.78\right)$. Thus, sampling the significant behaviors from two different studies still produces a subset of items that are internally consistent/reliable as in the previous studies.

There are 10 nonverbal and 10 verbal behaviors. The nonverbal behaviors are questioned first and then the verbal behaviors. It was presumed that, since these were not university level communication students, as was often the case in previous studies, it would not be noticeable to the subject that the behaviors were grouped in this fashion. This method of grouping the questions was chosen to engage the subject in

\footnotetext{
${ }^{8}$ Cronbach's alpha is a measure of the internal consistency or reliability, that is, it is a measure of how closely related a set of items are as a group. It can have values less than or equal to 1 , but only positive values make sense. Higher values of alpha are more desirable as they indicate a higher inter-item correlation and, in general, a value of 0.70 or higher is considered acceptable to show relatively high internal consistency in most social science research. (SPSS FAQ: What does Cronbach's alpha mean?)
} 
thinking continuously about one type of behavior, verbal or nonverbal, instead of jumping from one to the other multiple times.

As a measure of perceived cognitive learning, a question is then posed asking the subject to "On a scale of 0 to 4, how much have you learned in this class? (0 means haven't learned anything and 4 means you have learned more than in any other math class you've taken)." This measure of perceived cognitive learning is a scale adapted from Richmond et. al. (1987) and, although the scale is recognizably subjective, they argue that it is suitable for this type of measure because:

College students are adults with considerable experience in a school environment. We believe it is reasonable to expect them to estimate with considerable accuracy the amount they learn in a given class. In fact, it is likely that their estimate is at least as good as subjective grades provided by teacher in many classes. (p. 581)

Perceptions of impact. Previous research on immediacy behaviors assumes that high frequency of a behavior coupled with a high perception of cognitive learning means that the behavior is important to learning. However, just because a behavior is frequent and a subject perceives that they are learning a lot, does not necessarily mean that the behavior is a direct cause of learning or perception thereof. For this reason, this part of the survey deviates in methodology from previous research.

In this part of the survey a similar series of 10 verbal and 10 nonverbal behaviors are addressed. However, in this section, for each behavior subjects are asked to indicate on a scale from -2 (strong negative impact) to 2 (strong positive impact) how much they feel each teacher behavior impacts their learning. The purpose of this 
portion of the survey is to determine, by asking directly, which behaviors the subjects perceive to be most beneficial to their cognitive learning.

As a measure of perceived cognitive learning, subjects are then asked how much they think they could learn if they had a mathematics teacher that displayed the behaviors that were indicated to positively impact their learning. This question is designed to examine if students feel that if teachers communicated and behaved in desirable ways that it would affect their cognitive learning.

Additionally, a short answer question is posed at the end of this section asking subjects to think about the math teacher that displays all of the behaviors that were indicated as 1 (slight positive impact) or 2 (strong positive impact) and write down what is it about those behaviors that help them to learn mathematics. The purpose of this question is for insight into what it is about the behaviors that make them important to the subjects.

Demographics. The third, and final, part of the survey is a demographics questionnaire which includes questions about the race of the subject, race of the teacher, and age of the subject. Most importantly, the demographics information will be used for grouping the responses into racial groups for comparison (see Appendix $F$ for survey).

\section{Data Collection Procedures}

Time frame. Mathematics teachers at the subject institutions were solicited for 
access to their mathematics classes in late February/early March of 2010. If an instructor agreed to participate, the researcher used a short portion of his or her class to ask for students to volunteer to participate in the study by filling out a 10 minute survey. Late February/early March was chosen to assure that students had at least a few weeks of class time with their current mathematics instructor so that they were better able to engage the Perceptions of Frequency portion of the survey and, in turn, the Perceptions of Impact portion of the survey.

Survey administration protocol. On the day that the survey was to be administered, the researcher entered the class during the final fifteen minutes of the class period. The researcher distributed the surveys to the subjects and then read the survey administration protocol (see Appendix G). The subjects either filled out the survey or, if they chose not to participate, waited until the survey time ended. At the end of the survey time, subjects returned the surveys, blank or otherwise, to the researcher. The surveys were placed in a coded manila envelope for transport. Again, the code designated the school, math subject, date and time the survey was administered.

\section{Data Preparation}

Quantitative survey data. Each student's numerical response to each survey item was entered in the spreadsheet program SPSS/PASW. To ensure accurate input of data, each student's survey responses were keyed in, and then his/her scores were 
double checked against the keyed-in data.

Demographics. The racial data collected were summarized by college and math classes. In addition, racial demographics for the county, region, and state have been compiled for comparison purposes.

Qualitative survey data. Each student's written response to the open ended survey item was typed into a cell in the same spreadsheet as the quantitative data.

\section{Data Analysis}

The intent of this research was to examine the relationships between mathematics teacher immediacy behaviors and perceived cognitive learning. To answer each research question, bivariate statistical methods using Pearson product-moment correlations were performed to determine the linear dependence between variables. Correlation coefficient ( $r$ ) values closer to 1 or -1 indicate stronger relationships between variables where values closer to 0 indicate a weaker relationship between variables. As replicated from Richmond et. al. (1987), a single significance criteria is used for all groups, regardless of size. In this case, the smallest group of subjects for the groups being considered was Whites making this group the most stringent group in terms of statistical significance.

It should be noted that the demographic categories have been modified from the original survey to match the demographics list provided by the National Center for Educational Statistics. The Hispanic and Mexican/Mexican American group were 
merged under the group called "Hispanic". Then, because the American Indian, Pacific Islander, Multi-racial including Black, and Multi-racial non-Black groups each had fewer than twenty participants each they were collected into a group that is referenced as "Other." Since this group, and its subgroups, are not referenced in other studies and are not the focus of this study, statistical results for this group are only reported as part of the overall calculations which include all participants from all groups. So, for the purposes of analysis, the demographic groups are White, Black, Hispanic, and Asian. For a table of the descriptions of which survey participants are included in these groups see Appendix $\mathrm{H}$.

Perceptions of frequency. The Perceptions of Frequency portion of the survey was analyzed and compared to the previous research upon which it was modeled. A Pearson's correlation was performed by group on the responses for perceived cognitive learning measure using SPSS/PASW. The same correlation was then performed across all groups to give an overall result. The $r$-values were examined based on the criteria for statistical significance for the White group, as stated above. At the 0.05 significance level a value of 0.25 for Pearson's $r$ implies significance for Whites and was used as the criterion across groups.

Perceptions of impact. The Perceptions of Impact portion of the survey was analyzed similarly to Perceptions of Frequency.

Analysis of the short answer question was be qualitative in nature and examined 
students' reflections on how the immediacy behaviors selected as most impactful on mathematics learning actually help students learn. To determine if students' responses reflected distinct categories of perceptions of impact, student responses were separated by racial category and scanned for common key words or phrases. When four instances of a specific key word or phrase or synonymous word or phrase were noted, then a new category was created (note that four represents at least five percent of respondents within each group). The tally of the number of students in each category revealed relative levels of importance students attached to their most important immediacy behaviors.

These methods, as adapted from previous research, will present the results of this study in a way that will not only answer the research questions, but also offer an academic avenue for the beginnings of the discussion about communication in regards to the mathematics education of African American community college students. 


\section{Results}

To determine the relationship between immediacy and perceived cognitive learning, correlations were computed for the immediacy scores and the perceived cognitive learning for each demographic group and for the sample as a whole. Scores for items from the survey that were presumed to be non-immediate based on the previous research were reversed for the purposes of analysis (e.g. has a tense body, uses a dull voice).

First it should be noted that, across all ethnic groups, a positive overall correlation was found between immediacy and learning and between each immediacy behavior and learning. This suggests positive cross-cultural effects of teacher immediacy behaviors on learning in the community college mathematics classroom. Such results are consistent with previous research which has reported that teacher immediacy is positively related to learning across ethnic groups (Sanders \& Wiseman, 1990).

\section{Perceptions of Frequency}

Tables 1 and 2 summarize the correlations between the immediacy behaviors and the perceived cognitive learning measure for the Perceptions of Frequency portion of the survey. In general it is noted that there were more verbal than nonverbal behaviors that were significantly related to perceived cognitive learning and only "praises student work" was significantly related to perceived cognitive learning across 
groups. For Black and White students, verbal rather than nonverbal behaviors were more significantly related to learning while, for Hispanic students, both verbal and nonverbal behaviors were significantly related. For Asian and White students, relatively few behaviors, verbal or nonverbal, were found to be significantly related to perceived cognitive learning. Although smiling at the class and not looking at the board/notes were the only nonverbal behaviors shown to be significant for African Americans, each of these behaviors was also found to be significant for at least two other groups. In the case of smiling at the class, Hispanics and Asians also reported a significant positive relationship with cognitive learning. Reports for Whites, Hispanics, and Blacks show a positive relationship to "not looking at the board/notes." In agreement with Sanders and Wiseman (1990), it was shown that maintaining eye contact was not as important to Blacks as to Whites and Hispanics who reported a significant positive relationship to perceived cognitive learning.

There were a number of behaviors that were not found to be related to the learning across groups. Namely, (a) gestures when talking, (b) makes physical contact, (c) stands close to students, (d) avoids standing behind a podium, (e) has an animated voice, (f) solicits the viewpoints of students, and (g) discusses issues unrelated to class.

Overall correlations are reported in the last column of Tables 1 and 2 to give the overall view of how the responses related to the perceived cognitive learning measure across groups. 
Table 1

Correlation Between Nonverbal Immediacy Behaviors and Perceived Cognitive Learning by Race-Perceptions of Frequency

\begin{tabular}{lccccc}
\hline Nonverbal Behavior & $\begin{array}{c}\text { White } \\
(n=63)\end{array}$ & $\begin{array}{c}\text { Black } \\
(n=153)\end{array}$ & $\begin{array}{c}\text { Hispanic } \\
(n=110)\end{array}$ & $\begin{array}{c}\text { Asian } \\
(n=150)\end{array}$ & $\begin{array}{c}\text { Overall } \\
(n=529)\end{array}$ \\
\hline Gestures when talking & .00 & .23 & .11 & .11 & .15 \\
Smiles at Indiv. Students & .12 & .17 & $.36^{*}$ & .23 & .21 \\
Smiles at class & .19 & $.29 *$ & $.36^{*}$ & $.30^{*}$ & $.30^{*}$ \\
Makes physical contact & .04 & .08 & .12 & .06 & .06 \\
Moves around classroom & .07 & .01 & $.33^{*}$ & .17 & .16 \\
Stands close to students & .13 & .04 & .12 & .09 & .08 \\
Maintains eye contact & $.37^{*}$ & .22 & $.45^{*}$ & .08 & .12 \\
Has tense body [R] & .19 & .16 & .16 & -.06 & .11 \\
Looks at board/notes [R] & $.28^{*}$ & $.28^{*}$ & $.25^{*}$ & .14 & $.25^{*}$ \\
Stands behind podium [R] & -.05 & .04 & .09 & .03 & .05 \\
\hline
\end{tabular}

* indicates statistically significant result at the $p=0.05$ level

$[R]$ indicates reverse coding

The across group overall correlation shows significant values for smiling at the class, having a relaxed body, encouraging students to talk, using humor, using student names, praising student work, and referring to "our" class.

Although many immediacy behaviors were shown to be positively related to learning, only "praises student work" was shown to be positively related to cognitive learning across groups contrary to the findings of Sanders and Wiseman (1990) which showed seven such behaviors. Also, there were seven behaviors that, across groups, were shown to not be significantly related to cognitive learning. These behaviors include: (a) gestures when talking, (b) makes physical contact, (c) stands close to students, (d) does not stand behind a podium, (e) has an animated voice, (f) solicits the viewpoints of students, and (g) discusses issues unrelated to class. Here we see some overlap from 
Table 2

Correlation Between Verbal Immediacy Behaviors and Perceived Cognitive Learning by Race-Perceptions of Frequency

\begin{tabular}{lccccc}
\hline \multicolumn{1}{c}{ Verbal Behavior } & $\begin{array}{c}\text { White } \\
(n=63)\end{array}$ & $\begin{array}{c}\text { Black } \\
(n=153)\end{array}$ & $\begin{array}{c}\text { Hispanic } \\
(n=110)\end{array}$ & $\begin{array}{c}\text { Asian } \\
(n=150)\end{array}$ & $\begin{array}{c}\text { Overall } \\
(n=529)\end{array}$ \\
\hline Uses personal examples & .18 & $.28^{*}$ & $.25^{*}$ & .08 & .20 \\
Encourages students to talk & $.28^{*}$ & $.34^{*}$ & $.35^{*}$ & .14 & $.29^{*}$ \\
Uses humor & $.25^{*}$ & $.31^{*}$ & $.27^{*}$ & .18 & $.25^{*}$ \\
Uses students' names & .22 & .23 & $.25^{*}$ & $.30^{*}$ & $.28^{*}$ \\
Uses a dull voice [R] & .13 & .23 & .20 & .06 & .20 \\
$\begin{array}{l}\text { Praises student work } \\
\text { Asks about assignments }\end{array}$ & $.27^{*}$ & $.33^{*}$ & $.31^{*}$ & $.32^{*}$ & $.36^{*}$ \\
$\begin{array}{l}\text { Refers to "our" class } \\
\text { Solicits viewpoints of }\end{array}$ & .24 & $.32^{*}$ & .16 & .18 & .19 \\
students & .17 & $.32^{*}$ & $.27^{*}$ & .11 & $.27^{*}$ \\
$\begin{array}{l}\text { Discusses issues unrelated to } \\
\text { class }\end{array}$ & .09 & .07 & .11 & .14 & .14 \\
* indicates statistically significant result at the $p=0.05$ level & & & .04 \\
[R] indicates reverse coding & & & & & \\
\hline
\end{tabular}

the Sanders and Wiseman's research that also concluded that (b), (c) and (g) were not significant to learning across groups. However, there are quite a few differences.

Comparing and contrasting African Americans with other group shows similarities and differences from the other groups studied. For Black students, significant relationships were obtained between perceived cognitive learning and (a) smiles at class, (b) does not look at the board/notes, (c) uses personal examples, (d) encourages students to talk, (e) uses humor, (f) praises student work, (g) asks about assignments, and (h) refers to "our" class. Examining these items, there are three times as many verbal as nonverbal behaviors. In contrast, other groups saw more similarity in 
the number of significant behaviors from both categories.

Similarities between Blacks and other groups were also noted. Most notably, seven of the eight behaviors that were shown to be positively related to learning for Black students, the exception being "asks about assignments," were also found to be positively related to learning for Hispanic students. Similarly, six of the eight significant behaviors, the exceptions being "asks about assignments" and "smiles at class," were shown to be positively related to the learning of White students as well.

While immediacy appears to be positively associated with learning across groups, it appears that one immediacy behavior is particularly significant for African Americans. It was shown that for Black students asking about assignments was positively related to learning, indicating that this behavior may be uniquely important to Black mathematics students rather than other groups.

Overall, what can be seen is that, across groups, the majority of the immediacy behaviors studied have a positive correlation with perceived cognitive learning. This indicates that, at worst, some immediacy behaviors have a neutral affect on learning. In particular, eight of the 20 behaviors were found to be significantly positively related to learning while there were five other behaviors that did not have significant relationships, but had relationships that are noteworthy. These behaviors include (a) gestures when talking, (b) maintains eye contact, (c) uses personal examples, (d) uses student names, and (e) has an animated voice. Thus 13 of 20 behaviors, based on the methodologies of previous research, have been shown to positively influence the 
perceived cognitive learning of African American community college mathematics students.

\section{Perceptions of Impact}

This part of the study sought to reveal via the experimental method of direct questioning which immediacy behaviors community college mathematics students find most beneficial to their cognitive learning and how these behaviors help them learn.

Survey items. Tables 3 and 4 summarize the correlations between the immediacy behaviors and the perceived cognitive learning measure for this portion of the study. Results show very few behaviors that were significantly related with perceived cognitive learning.

Table 3

Correlation Between Nonverbal Immediacy Behaviors and Perceived Cognitive Learning by Race-Perceptions of Impact

\begin{tabular}{lccccc}
\hline \multicolumn{1}{c}{ Nonverbal Behavior } & $\begin{array}{c}\text { White } \\
(n=63)\end{array}$ & $\begin{array}{c}\text { Black } \\
(n=153)\end{array}$ & $\begin{array}{c}\text { Hispanic } \\
(n=110)\end{array}$ & $\begin{array}{c}\text { Asian } \\
(n=150)\end{array}$ & $\begin{array}{c}\text { Overall } \\
(n=529)\end{array}$ \\
\hline Gestures when talking & -.02 & .17 & .19 & .12 & .10 \\
Smiles at Indiv. Students & -.07 & .17 & .09 & .13 & .13 \\
Smiles at class & .02 & .08 & .12 & $.25^{*}$ & .13 \\
Makes physical contact & .00 & .04 & .12 & -.01 & .04 \\
Moves around classroom & .09 & .02 & .19 & .13 & .08 \\
Stands close to students & .00 & .04 & $.27 *$ & -.09 & .01 \\
Maintains eye contact & .22 & .13 & .12 & .05 & .16 \\
Has a relaxed body & .01 & .12 & .17 & .15 & .13 \\
Looks at board/notes [R] & .09 & .11 & .21 & .09 & .14 \\
Stands behind podium [R] & -.19 & .05 & -.12 & .09 & .02 \\
\hline
\end{tabular}

* indicates statistically significant result at the $p=0.05$ level

$[R]$ indicates reverse coding 
Blacks had no behaviors correlate as significant while Whites had two behaviors (uses personal examples and encourages students to talk). Hispanics and Asians each had four behaviors show significance (stands close to students, uses students' names, praises student work, and refers to "our" class for Hispanics and smiles at class, uses humor, asks about assignments, and refers to "our" class for Asians). Overall correlations are noted the last column of Tables 3 and 4 . In general, the overall correlations are much lower than what was reported under Perceptions of Frequency.

Table 4

Correlation Between Verbal Immediacy Behaviors and Perceived Cognitive Learning by Race-Perceptions of Impact

\begin{tabular}{lccccc}
\hline \multicolumn{1}{c}{ Verbal Behavior } & $\begin{array}{c}\text { White } \\
(n=63)\end{array}$ & $\begin{array}{c}\text { Black } \\
(n=153)\end{array}$ & $\begin{array}{c}\text { Hispanic } \\
(n=110)\end{array}$ & $\begin{array}{c}\text { Asian } \\
(n=150)\end{array}$ & $\begin{array}{c}\text { Overall } \\
(n=529)\end{array}$ \\
\hline Uses personal examples & $.26^{*}$ & .13 & .04 & .14 & .16 \\
Encourages students to talk & $.39 *$ & .01 & .04 & .19 & .10 \\
Uses humor & .18 & .00 & .02 & $.26^{*}$ & .09 \\
Uses students' names & .09 & -.02 & $.27^{*}$ & .17 & .07 \\
Has an animated voice & -.01 & .06 & .21 & .11 & .08 \\
Praises student work & .03 & .01 & $.33^{*}$ & .19 & .09 \\
Asks about assignments & .18 & .09 & .18 & $.25^{*}$ & .11 \\
Refers to "our" class & -.09 & .18 & $.30^{*}$ & $.34^{*}$ & .15 \\
Solicits viewpoints of & -.09 & .13 & .19 & .15 & .11 \\
students & & & & & .04 \\
$\begin{array}{l}\text { Discusses issues unrelated } \\
\text { to class }\end{array}$ & .02 & .14 & -.23 & .00 & .04 \\
\hline
\end{tabular}

* indicates statistically significant result at the $p=0.05$ level $[R]$ indicates reverse coding

Short answer. The short answer question asked respondents to describe how the behaviors denoted as positively impacting learning helped them to learn. Table 5 
shows the number of respondents by race.

Table 5

Number of respondents by Race to the Short Answer Question

\begin{tabular}{cccccc}
\hline White & Black & Hispanic & Asian & Other & Total \\
\hline 39 & 67 & 53 & 77 & 39 & 275 \\
\hline
\end{tabular}

Results from these questions revealed that, across groups, there were three main themes within the responses. Subjects indicated that immediacy behaviors made the instructor personable/relatable, created a safe and relaxing classroom environment, and kept the class lively and interesting.

When subjects felt that the instructor was personable/relatable, they reported that it made the instructor seem more approachable and made subjects feel more comfortable overall. Subjects also reported that they felt that the instructor cared about them which made the students want to come to class and want to learn more. One African American subject noted that it made her "feel wanted and able" and another reported that "it just shows that you have support and that they want you to succeed." This theme was far more prominent in the responses from the African American group but also appeared in responses across groups.

Respondents also indicated that immediacy behaviors created a more relaxed and less stressful class environment making it more comfortable to be in class. One African American subject described feeling a "positive sense of community." Other 
descriptors used for this environment were welcoming, friendly, inviting, positive, and safe. "Safe" indicates that if instructors do not use immediacy behaviors in the mathematics setting that students may have fears or anxiety about "[speaking] up, [asking] for help, and [being] afraid of feeling dumb if they make a mistake."

Another theme was keeping the class engaging and interesting to prevent boredom or falling asleep. A number of African American respondents discussed falling asleep in classes that were "boring" or where the instructor was not as "animated." Some respondents noted that these behaviors make it seem like the instructor is not interested in being there and, according to one subject, "if they look like they aren't interested in being here, then I'm not either."

These results, in general, fall in line with the results of previous studies done in other subject areas. The Perceptions of Frequency portion of the study seem to very closely replicate the results from previous studies indicating that immediacy does positively affect perceived cognitive learning and that, although some behaviors show statistical significance, all of the immediacy behaviors studied have a positive or neutral correlation with perceived cognitive learning. The Perceptions of Impact portion of the study yielded quite a different set of results that did not necessarily follow the results of Perceptions of Frequency. The results of the correlations between perception of impact and perceived cognitive learning indicate that students across groups may not think that immediacy affects their cognitive learning. However, in the short answer portion students clearly indicated that immediacy did have an impact. A discussion of the 
possible reasons for this discrepancy will be presented in the section that follows. 


\section{Discussion}

The current study shows that, using the methodologies from previous research (Perceptions of Frequency), a different subset of communication behaviors is shown to be effective in community college mathematics classrooms, than in the other types of classes that have previously been studied. It has also shown that the experimental method of direct questioning regarding which behaviors affect learning (Perceptions of Impact) does not produce the same results and, in fact, concludes that few communication behaviors are effective.

\section{Perceptions of Frequency}

The behaviors chosen for this research were, in previous research, shown to have a positive relationship with cognitive learning (Gorham, 1988; Sanders \& Wiseman, 1990). However, in the current study, only a small subset of these behaviors was shown to have a significant positive relationship with cognitive learning and, generally, there was less of a positive relationship than found in previous studies (Gorham, 1988;

Sanders \& Wiseman, 1990).

Across groups, the results show that verbal, rather than nonverbal, behaviors were more significantly related to perceived cognitive learning. This is not necessarily surprising considering that these students were being taught with traditional teaching methods with the teacher in the front of the room lecturing and writing notes on the 
board while students were at their desks ${ }^{9}$. Students in this type of classroom environment are generally frantically copying the notes from the board while listening and trying to comprehend the instructor and so are less likely to concentrate, or even be able to take note of, the nonverbal communication employed by the instructor.

Nonverbal. Although only smiling at the class and not looking at the board/notes were shown to be significant for African Americans, each of these behaviors was also found to be significant for at least two other groups. These two behaviors together are those that would be the easiest for students to notice in the mathematics classroom setting as described and show that, at minimum, the instructor is paying attention to the students in the class. In other words, they show the student that the teacher knows that he or she is there and transmits the feeling of acknowledgment. This suggests that, although they do not appear to be as salient as verbal behaviors within the mathematics classroom, some nonverbal behaviors do affect the perceived cognitive learning across groups. It also may explain why seven of the ten nonverbal behaviors studied show non-significant positive relationships with cognitive learning.

In agreement with Sanders and Wiseman (1990), this study shows that maintaining eye contact is important to Whites and Hispanics but not to Blacks. This

\footnotetext{
${ }^{9}$ The researcher generally arrived to each subject classroom and waited outside for approximately 15 minutes. During this time, the classroom was observed from the exterior. Traditional teaching methods were employed in all of the classrooms observed.
} 
difference in importance may stem from eye contact patterns which show that African Americans make more eye contact while they are talking rather than when they are listening (reverse for European Americans) (Hecht, Jackson, \& Ribeau, 2003). It has also been shown that African Americans make less eye contact with authority figures (Hecht, Jackson, \& Ribeau, 2003).

Thus, due to the structure of mathematics classes, it would seem that nonverbal behaviors, although less important, do play a small role in the cognitive learning of African Americans.

Verbal. African American culture is predominantly oral in nature and highly values verbal skills, especially in narrative frameworks (Hecht, Jackson, \& Ribeau, 2003). This may explain why far more verbal than nonverbal behaviors were shown to be significantly positively related to the perceived cognitive learning of African American community college students. The results show that for these students, six of the ten verbal behaviors were significantly positively related to perceived cognitive learning. The six behaviors include using personal examples, encouraging students to talk, using humor, praising student work, asking about assignments, and referring to "our" class.

To expand on the oral nature of African American culture, it is also noted that, even in speaker-audience situations, dialogue is interactive. That is, auditory response from the audience is important and is a signal of an effective speaker (Hecht, Jackson, \& Ribeau, 2003). Thus, encouragement to talk and interact with the instructor and the class, based on cultural considerations, are important for African Americans. Positivity 
and emotionality are also highly valued in African American communication (Hecht, Jackson, \& Ribeau, 2003) and these values explain the connection between perceived cognitive learning and using humor and praising student work. Using personal examples, asking about assignments, and referring to "our" class are representative of the African American cultural collectivism and reflect interconnectedness and interrelatedness. Using personal examples is a form of sharing of self that characterizes the African American family structure where asking about assignments and referring to "our" class symbolize interrelatedness and unification. In the latter, we see that the instructor cares enough to inquire how they are doing with the assignments and is creating a classroom environment for the student to feel a part of and participate in ("our" class).

Using the students' names and not using a dull voice were shown to a have a positive but not quite significant connection with perceived cognitive learning. These two behaviors also fall into categories that are valued within African American communication, collectivism and emotionality, respectively. The use of student names indicates that the instructor cares enough about students to remember their names even though he or she may have over one hundred other names to remember. Not using a dull voice characterizes a sense of aliveness and emotional vitality that is highly valued in oral communication within the African American culture (Hecht, Jackson, \& Ribeau, 2003). 


\section{Perceptions of Impact}

The data collected for this portion of the study produced various unexpected results. The data indicate that the experimental method of direct questioning used in Perceptions of Frequency did not produce any behaviors that were significantly related to perceived cognitive learning of African American community college students. This was an unanticipated result because all of the previous similar studies produced a number of behaviors that were found to be significant to cognitive learning (e.g. Gorham, 1988 and Sanders and Wiseman, 1990) and it did not seem likely that these behaviors would correlate so highly in other studies and not here. It is believed that these unexpected results may have been due to the survey instrument itself. The short answer responses indicated that some subjects were referencing the Perceptions of Frequency portion of the survey and basing their responses on the behaviors of their current instructor. This indicates that the subjects misunderstood the directions or did not read them at all. Because African American culture, in general, is oral in tradition, the collection of data in this way may have been more difficult to engage for African American subjects. However, similar results were noted across cultures further implicating the Perceptions of Frequency portion of the survey instrument. Thus it is believed that the conclusion that there are no significant behaviors that impact the mathematics learning of African American community college students may be questionable.

Although the first section of Perceptions of Impact does not appear to yield 
fruitful results, the responses to the short answer question indicate that immediacy behaviors are important to the learning of community college mathematics students in general and, in particular, for African American students. For African American subjects, instructor involvement, caring, and creation of a relaxed and comfortable environment were the most reported indicators of how immediacy helps them to learn. One important note to make here is that many of the African American respondents who addressed these themes did so in a way that might indicate that these are feelings they do not often feel in mathematics classrooms. For example:

Student 1: "It shows the teacher actually cares about their students." Student 2: "Shows the teacher is involved and interested in teaching us." Subject 3: "I don't like to feel like a number."

Subject 4: "I feel safe to ask questions in class and approach the teacher outside of class."

Student 1's use of the term "actually" indicates a note of annoyance which may stem from an educational experience lacking mathematics teachers, and possibly teachers in general, that they deem as caring. With the results showing that caring teachers made subjects want to come to class and want to learn, this is a very important feeling for an instructor to exude. Just as important is that it be genuine. That is, the instructor should actually care about their students in more than a theoretical way. In studies of African American communication, this realism is crucial to building relationships (Hecht, Jackson, \& Ribeau, 2003).

Students 2 and 3 seem to want the instructor to show that he or she wants to teach students and not objects. This goes back to Friere's concept (2009) of humanizing 
students mentioned earlier.

It should also be noted that these themes were prevalent across groups but seemed to have a lack of expectation of fruition in the African American responses. So it would appear that African American community college students have not had mathematics teachers who met their needs insofar as creating a learning environment that made them feel comfortable. Immediacy is a tool for creating this change.

\section{Limitations}

Although a methodology similar to that used in previous research was used to extract the desired data, there are limitations. This study was about communication behaviors and, since some cultures including that of African Americans, have an oral tradition (Hecht, Jackson, \& Ribeau, 2003), gathering the bulk of the information via survey may have left gaps in the information. Also, this study was done across levels of mathematics from arithmetic to calculus, including self-paced arithmetic courses. It is possible that some subjects did not have the reading comprehension required to fully understand the vocabulary and specific directions within the survey, which would lead to erroneous or uninformed responses. Since there were verbal instructions on how to fill out the survey, some subjects may have encountered receiver apprehension causing anxiety. Although subjects were informed that the survey was not an evaluation of their instructor, there may have been a student inclination to interpret the survey as such and introduce bias for teachers that they did not perceive as "good." 
There were also design issues which should be taken into account. First, and foremost, this research was performed in mathematics classrooms where it is likely that many of the subjects have not previously considered in any depth how their instructor's behavior influences their learning. Much of the previous research was performed at the university level with communication students or students of unnamed majors but not specifically mathematics (Gorham, 1988; Sanders \& Wiseman, 1990; Witt \& Wheeless, 2001; Chesebro \& McCroskey, 2001). The university level communications students would be familiar with communication behaviors and their effects offering researchers a pool of informed and knowledgeable responses. The subjects of this study did not have this knowledge base which may account for the number of subjects that did not complete the survey in its entirety, resulting in possible effects on the quantity and quality of the results. It is also noted that the design of the survey used methods of previous research in the Perceptions of Frequency portion to obtain information as well as to serve as a vehicle for Perceptions of Impact. This may have been confusing to subjects who interpreted Perceptions of Impact to be related to Perceptions of Frequency when this was not the intention. The Perceptions of Impact portion also asked students to think about a hypothetical situation and African Americans tend to think in contextually-based situations that may not have been reachable by this study (Tate, 1995).

In addition, there are factors for which this research was not designed to account. Socioeconomic status, gender and race of instructors, and level of 
mathematics are examples of such factors that, if taken into account, could produce different results.

\section{Generalizability of Results}

This research was performed at two racially diverse community colleges that serve students mostly from urban city environments and their suburbs. Thus the information presented here may be generalized to similar settings, but it would not be recommended to generalize outside of similar environments.

\section{Importance of Results}

The results of the current study provide a starting point for further research. The results indicate that immediacy includes methods of communication that are helpful for instructors to incorporate into their classroom instruction technique to increase the cognitive learning of their African American students as well as students of other groups.

The results also provide evidence that ideas that have been studied in other subject areas can be relevant to mathematics education and should not be discounted because their relevance has yet to be shown. Instead, potentially relevant concepts should be carefully considered and studied within the mathematics education context to prove or disprove their relevance. In this study, concepts from communications and social psychology show very promising results in the mathematics education of African American community college students and further research should be considered to 
expand upon these findings.

\section{Suggestions for Further Research}

The results of this study suggest that immediacy is important to the perceived cognitive learning of African American community college students and that further research is required to gain a complete understanding of immediacy and how it manifests in this context. This study took the approach of using a survey instrument with a short answer portion. As discussed above, the Perceptions of Impact portion of the survey may not have been engaged by the students as it was originally anticipated. Thus, it is suggested that further research involve a more interactive approach with the subjects, possibly in the form of interviews or student forums, where the subjects can dialogue about these questions and request clarification of questions as required. It is also suggested that if the above research indicates significant instructor communication behaviors that this research be expanded to primary and secondary school age African American students to determine if these results extend outside of the community college realm. 


\section{Conclusion}

This was a preliminary research study using the methodologies from previous research (Perceptions of Frequency) as well as an additional experimental method of direct questioning (Perceptions of Impact) to determine what communication behaviors, if any, significantly affect the perceived cognitive learning of African American community college students in mathematics education.

One of the intentions of this study was to be a starting point for the integration of communications research into realm of mathematics education. The important difference between this and other mathematics education research is this study's focus on how mathematics instructors are communicating and not what is being communicated. That is, this study sought not to examine what topics mathematics instructors are teaching or how the topics were being presented in terms of curriculum but how instructor behaviors, regardless of mathematical topic, are perceived by African American community college students. In this case, the premise is that appropriate and effective communication by an instructor precedes anything in the curriculum and, because all communication includes affect, communication behaviors are a vital part of any pedagogy.

The study consisted of a voluntary survey that was administered to participants from two community colleges in the San Francisco Bay Area. Participants were enrolled in mathematics classes that ranged from arithmetic through calculus.

The survey was broken into two parts. The first, Perceptions of Frequency, 
utilized the methodologies presented in previous research outside of mathematics to show that instructor immediacy behaviors positively affect the perceived cognitive learning of African American community college students. Results indicated that $40 \%$ of the immediacy behaviors studied had a significant effect on the perceived cognitive learning of this group. The remaining $60 \%$ of the behaviors either had a positive or neutral correlation with perceived cognitive learning. This suggests that the use of immediacy behaviors have an overall positive effect on the perceived cognitive learning of African American community college students.

The second part of the survey, Perception of Impact, sought to reveal via the experimental method of direct questioning what immediacy behaviors community college mathematics students find most beneficial to their cognitive learning. Previous research on immediacy behaviors assumed that high frequency of a behavior coupled with a high perception of cognitive learning meant that the behavior is important to learning. However, it is not necessarily clear that a frequently occurring immediacy behavior directly causes learning or the perception thereof. Thus this portion of the survey directly asked subjects which behaviors they thought most impacted their cognitive learning and why. Results of this portion of the study revealed that this method of obtaining information from subjects resulted in very few immediacy behaviors that were significantly related to perceived cognitive learning. However, the short answer portion of this part of the study indicated that immediacy behaviors are important to the perceived cognitive learning of community college mathematics 
students in general and, in particular, for African American students. For African American subjects, instructor involvement, caring, and creation of a relaxed and comfortable environment were the most reported indicators of how immediacy helps them to learn.

The results of this study suggest that immediacy is important to the perceived cognitive learning of African American community college students and that further research is required to gain a complete understanding of immediacy and how it manifests in the context of mathematics education and across cultures within this context. 


\section{References}

Acculturation. (n.d.). In Merriam-Webster Online Dictionary (11th Ed.). Retrieved from http://www.merriam-webster.com/dictionary/acculturation

Andersen, J.F. (1979). Teacher immediacy as a predictor of teaching effectiveness. In D. Nimmo (Ed.), Communication Yearbook 3 (pp. 543-559). New Brunswick, New Jersey: Transaction Books.

Anderson, P. (1985). Nonverbal immediacy in interpersonal communication. In A. W. Siegman, \& S. Feldstein (Eds.), Multichannel Integrations of Nonverbal Behavior (pp. 1-36). Hillsdale, NJ: Lawrence Erlbaum Associates.

Ayres, J., Wilcox, A. K., \& Ayres, D.M. (1995). Receiver apprehension: An explanatory model and accompanying research. Communication Education, 44, 223-235.

Banks, J.A. (1995). Multicultural education and curriculum transformation. Journal of Nego Education, 64 (4), 390-400.

Bashford, A., \& Levine, P. (2010). The oxford handbook of the history of eugenics. New York: Oxford University Press.

Baum, B.D. (2006). The rise and fall of the Caucasian race: A political history of racial identity. New York: NYU Press.

Bishop, A.J. (1988). Mathematics education in its cultural context. Educational Studies in Mathematics, 19, 179-191.

Brand, B.R., Glasson, G.E., \& Green, A.M. (2006). Sociocultural factors influencing students' learning in science and mathematics: An analysis of the perspectives of African American students. School Science and Mathematics, 106 (5), 228-236.

Chattel. (n.d.). In Merriam-Webster Online Dictionary (11th Ed.). Retrieved from http://www.merriam-webster.com/dictionary/chattel

Chesebro, J., \& McCroskey, J. (2001). The relationship of teacher clarity and immediacy with student state receiver apprehension, affect, and cognitive learning. Communication Education, 50 (1), 59-68.

Cobb, P., \& Hodge, L.L. (2002). A relational perspective on issues of cultural diversity and equity as they play out in the mathematics classroom. Mathematical Thinking and Learning, 4 (2\&3), 249-284. 
Communicate. (n.d.). In Merriam-Webster Online Dictionary (11th Ed.). Retrieved from http://www.merriam-webster.com/dictionary/communicate

D'Ambrosio, U. (1985). Ethnomathematics and its place in the history and pedagogy of mathematics. For the Learning of Mathematics, 5, 44-48.

Daniels, T., \& Whitman, R.F. (1979). The effects of message structure, required recall structure, and receiver apprehension upon the recall of message information. Green Bay: University of Wisconsin.

Dr. Welsing \& Shockley [sic] Debate Pt 4. (1974). Retrieved November 13, 2010, from www.youtube.com/watch?v=UMeNZjK2FSs

Ellis, K. (2004). The impact of perceived teacher confirmation on receiver apprehension, motivation, and learning. Communication Education, 53 (1), 1-20.

Eugenics. (n.d.). In Brittanica Online Encyclopedia. Retrieved from http://www.britannica.com/EBchecked/topic/195069/eugenics

Eugenics. (n.d.). In Merriam-Webster Online Dictionary (11th Ed.). Retrieved from http://www.merriam-webster.com/dictionary/eugenics?show=0\&t=1289704051

Eurocentrism. (n.d.). In Merriam-Webster Online Dictionary (11th Ed.). Retrieved from http://www.merriam-webster.com/dictionary/eurocentric

Feagin, J.R., \& Feagin, C.B. (2003). Racial and ethnic relations (7th ed.). Upper Saddle River, NJ: Pearson Education, Inc.

Friere, P. (2009). Pedagogy of the oppressed (30th anniversary ed.). New York: The Continuum International Publishing Group, Inc.

Gorham, J. (1988). The relationship between verbal teacher immediacy behaviors and student learning. Communication Education, 37, 40-53.

Hacker, A. (1992). Two nations: Black and white, separate, hostile, unequal. New York: Charles Scribner's Sons.

Harris, C.I. (1993). Whiteness as property. Harvard Law Review, 106 (8), 1701-1791.

Hecht, M.L., Jackson, R.L., \& Ribeau, S.A. (2003). African American communication: Exploring identity and culture. Mahwah, NJ: Lawrence Erlbaum Associates.

Identify. (n.d.). In Merriam-Webster Online Dictionary (11th Ed.). Retrieved from http://www.merriam-webster.com/dictionary/identify 
Joseph, G.G. (1997). Foundations of eurocentrism in mathematics. In A.B. Powell, \& M. Frankenstein (Eds.), Ethnomathematics: Challenging Eurocentrism in Mathematics Education (pp. 61-81). Albany, NY, USA: State University of New York Press.

Kelley, D., \& Gorham, J. (1988). The effects of immediacy on the recall of information. Communication Education, 37, 198-207.

King, J.E. (1991). Dysconscious racism: Ideology, identity, and the miseducation of teachers. Journal of Negro Education, 60 (2), 133-146.

Ladson-Billings, G. (1995). Making mathematics meaningful in a multicultural context. In W. Secada, E. Fennema, \& L. Adajian (Eds.), New Directions for Equity in Mathematics Education (pp. 126-145). New York: Cambridge University Press.

Ladson-Billings, G. (1994). The dreamkeepers: Successful teachers of African American children. San Francisco: Jossey-Bass.

Martin, D.B. (2006). Mathematics learning and participation as racialized forms of experience: African American parents speak on the struggle for mathematics literacy. Mathematical Thinking and Learning, 8 (3), 197-229.

Martin, D.B. (2007). Mathematics learning and participation in the African American context: The co-construction of identity in two intersecting realms of experience. In N. Nasir, \& P. Cobb (Eds.), Diversity, Equity, and Access to Mathematical Ideas (pp. 146-158). New York: Teacher's College Press.

Martin, D.B. (2000). Mathematics success and failure among African-American youth: The roles of sociohistorical context, community forces, school influence, and individual agency. Mahwah, New Jersey: Lawrence Erlbaum Associates.

Mehrabian, A. (1966). Immediacy: An indicator of attitudes in linguistic communication. Journal of Personality, 34 (1), 26-34.

Mehrabian, A. (1969). Some referents and measures of nonverbal behavior. Behavioral Research Methods and Instrumentation, 1, 213-217.

Mottet, T., \& Beebe, S.A. (2002). Relationships between teacher nonverbal immediacy, student emotional response, and perceived student learning. Communication Research Reports, 19 (1), 77-88.

Mottet, T., \& Patterson, B. (1996, November 23-36). Paper presented at the Annual Meeting of the Speech Communication Association. A conceptualization and 
measure of teacher verbal effectiveness. San Diego, CA.

Mottet, T., \& Richmond, V. (1997, April 10-13). Paper presented at the Annual Meeting of the Eastern Communication Association. An inductive analysis of verbal immediacy: Alternative conceptualization of relational verbal approach/avoidance strategies. Baltimore, MD.

Mottet, T., Garza, R., Beebe, S., Houser, M., Jurrells, S., \& Furler, L. (2008). Instructional communication predictors of ninth grade students' affective learning in math and science. Communication Education, 55 (3), 333-355.

Nasir, N. S. (2002). Identity, goals, and learning: Mathematics in cultural practice. Mathematical Thinking and Learning, 4 (2\&3), 213-247.

Oakes, J., Ormseth, T., Bell, R., \& Camp, P. (1990). Multiplying inequalities: The effects of race, social class, and tracking on opportunities to learn mathematics and science. Santa Monica: Rand Corporation.

Plax, T., Kearney, P., McCroskey, J., \& Richmond, V. (1986). Power in the classroom VI: Verbal control strategies, nonverbal immediacy and affective learning. Communication Education, 35, 43-55.

Powell, R., \& Harville, B. (1990). The effects of teacher immediacy and clarity on instructional outcomes: An intercultural assessment. Communication Education, 39, 369-379.

Preiss, R., Wheeless, L., \& Allen, M. (1990). The cognitive consequences of receiver apprehension: a meta-analytic review. Journal of Socal Behavior and Personality (5), 155-172.

Richmond, V., Gorham, J., \& McCroskey, J. (1987). The relationship between selected immediacy behaviors and cognitive learning. Communication Yearbook, 10, 574590.

Roberts, C. (1986). A validation of the Watson-Baker listening test. Communication Research Reports (3), 115-119.

Sanders, J.A., \& Wiseman, R.L. (1990). The effects of verbal and nonverbal teacher immediacy on perceived cognitive, affective, and behavioral learning in the multicultural classroom. Communication Education, 39, 341-353.

Scott, M., \& Wheeless, L. (1975). Communication apprehension, student attitudes, and levels of satisfaction. Western Journal of Speech Communication (39), 188-198. 
Shockley, W.B. (1972). Dysgenics, geneticity, raceology: A challenge to the intellectual responsibility of educators. Phi Delta Kappan International, 53 (5), 297-307.

SPSS FAQ: What does Cronbach's alpha mean? (n.d.). Retrieved November 30, 2010, from UCLA Academic Technology Services:

http://www.ats.ucla.edu/stat/spss/faq/alpha.html

Steele, C.M. (1997). A threat in the air: How stereotypes shape intellectual identity and performance. American Psychologist, 52 (6), 613-629.

Steele, C.M. (1999, August). Thin ice: Stereotype threat and black college students. The Atlantic Monthly, 44-54.

Steele, C.M., \& Aronson, J. (1995). Stereotype threat and the intellectual test performance of African Americans. Journal of Personality and Social Psychology, 69 (5), 797-811.

Tate, W.F. (1995). Returning to the root: A culturally relevant approach to mathematics pedagogy. Theory into Practice, 34 (3), 166-173.

U.S. Census Bureau. (2000). Quick Tables - American FactFinder. Retrieved November 27, 2010, from http://factfinder.census.gov/servlet/QTTable?_bm=y\&qr_name=DEC_2000_SF4_U_DP3\&-geo_id=01000US\&reg=DEC_2000_SF4_U_DP3:001|002|004\&-ds_name=DEC_2000_SF4_U\&_lang=en\&-redoLog=false

U.S. Census Bureau. (2000). Table DP-1. Profile of Demographic Statistics: 2000. Retrieved from http://censtats.census.gov/data/US/01000.pdf

U.S. Department of Education, Institute of Education Sciences, National Center for Educational Statistics. (2009-2010). "College 1" - College. Retrieved from http://nces.ed.gov/globallocator/col_info_popup.asp?ID="College 1 IPEDS ID \#"

U.S. Department of Education, Institute of Education Sciences, National Center for Educational Statistics. (2009). Grade 12 Reading and Mathematics 2009 National and Pilot State Results. Retrieved from http://nces.ed.gov/nationsreportcard/pdf/main2009/2011455.pdf

Wheeless, L. (1975). An investigation of receiver apprehension and social context dimensions of communication apprehension. The Speech Teacher (24), 261-268.

Wikler, D. (1999). Can we learn from eugenics? Journal of Medical Ethics, 25, 183-194. 
Witt, P.L., \& Wheeless, L.R. (2001). An experimental study of teachers' verbal and nonverbal immediacy and students' affective and cognitive learning.

Communication Education, 50 (4), 327-342. 


\section{Appendix A}

Participant Demographics of Participating Colleges

\begin{tabular}{|c|c|c|c|c|c|}
\hline Race $^{a}$ & $\mathrm{n}$ & Sample \% & School \% ${ }^{\mathrm{b}}$ & County $^{c}$ & State $^{c}$ \\
\hline \multicolumn{6}{|c|}{ College 1} \\
\hline White & 22 & 14.2 & 10.0 & 50.8 & 42.3 \\
\hline Black & 41 & 26.5 & 20.6 & 9.7 & 6.7 \\
\hline Hispanic & 19 & 12.3 & 9.1 & 20.9 & 34.3 \\
\hline Asian & 66 & 42.5 & 24.5 & 14.2 & 12.9 \\
\hline Other & 7 & 4.5 & 35.8 & 4.4 & 3.8 \\
\hline Total & 155 & 100.0 & 100.0 & 100.0 & 100.0 \\
\hline \multicolumn{6}{|c|}{ College 2} \\
\hline White & 41 & 11.0 & 13.6 & 36.7 & 42.3 \\
\hline Black & 112 & 29.9 & 25.3 & 13.5 & 6.7 \\
\hline Hispanic & 91 & 24.3 & 28.8 & 19.6 & 34.3 \\
\hline Asian & 84 & 22.5 & 22.0 & 25.7 & 12.9 \\
\hline Other & 46 & 12.3 & 10.3 & 4.5 & 3.8 \\
\hline Total & 374 & 100.0 & 100.0 & 100.0 & 100.0 \\
\hline \multicolumn{6}{|c|}{ 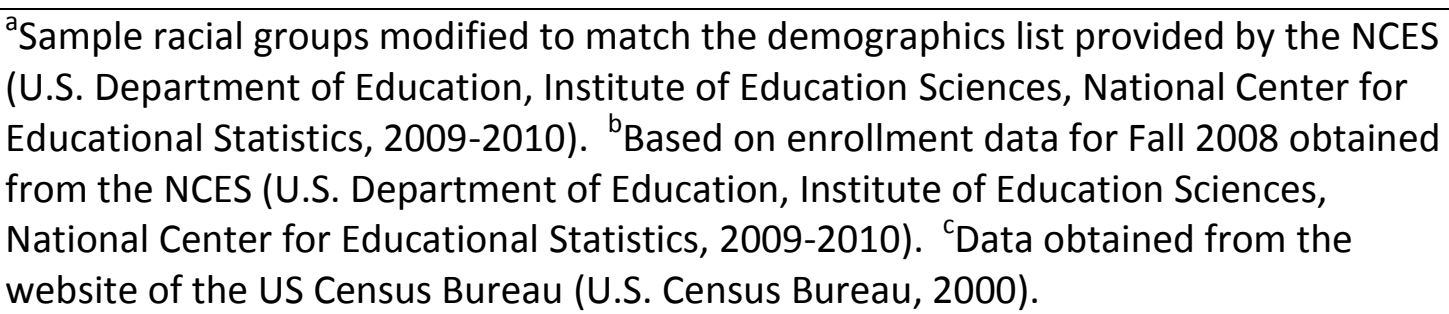 } \\
\hline
\end{tabular}




\section{Appendix B}

Demographic Information by Mathematics Course

\begin{tabular}{|c|c|c|c|c|c|c|c|c|c|}
\hline Race & Arith. & $\begin{array}{l}\text { Pre- } \\
\text { Alg. }\end{array}$ & $\begin{array}{c}\text { Elem. } \\
\text { Alg. }\end{array}$ & $\begin{array}{l}\text { Inter. } \\
\text { Alg. }\end{array}$ & Trig. & $\begin{array}{l}\text { Geo- } \\
\text { metry }\end{array}$ & $\begin{array}{c}\text { Discrete } \\
\text { Math }\end{array}$ & Stats & Calculus \\
\hline & \multicolumn{9}{|c|}{ College 1} \\
\hline White & 1 & 0 & 2 & 0 & 0 & 0 & 0 & 3 & 16 \\
\hline Black & 6 & 8 & 10 & 5 & 0 & 0 & 0 & 5 & 7 \\
\hline Hispanic & 0 & 7 & 0 & 3 & 0 & 0 & 0 & 3 & 6 \\
\hline Asian & 0 & 3 & 2 & 2 & 0 & 0 & 0 & 14 & 44 \\
\hline Other & 0 & 0 & 0 & 1 & 0 & 0 & 0 & 1 & 6 \\
\hline \multirow[t]{2}{*}{ Total } & 7 & 18 & 14 & 11 & 0 & 0 & 0 & 26 & 79 \\
\hline & \multicolumn{9}{|c|}{ College 2} \\
\hline White & 1 & 9 & 7 & 7 & 3 & 2 & 2 & 0 & 10 \\
\hline Black & 19 & 36 & 19 & 15 & 3 & 11 & 0 & 0 & 9 \\
\hline Hispanic & 6 & 16 & 18 & 14 & 9 & 5 & 5 & 0 & 18 \\
\hline Asian & 0 & 5 & 9 & 6 & 13 & 4 & 5 & 0 & 30 \\
\hline Other & 2 & 7 & 10 & 19 & 6 & 7 & 1 & 0 & 6 \\
\hline Total & 28 & 73 & 63 & 61 & 34 & 29 & 13 & 0 & 73 \\
\hline
\end{tabular}

Mathematics Course Abbreviations

Arith. Arithmetic

Pre-Alg. Pre-Algebra

Elem. Alg. Elementary Algebra

Inter. Alg. Intermediate Algebra

Trig. Trigonometry

Stats Statistics 


\section{Appendix C}

\section{Institutional Review Board Approval of Research}

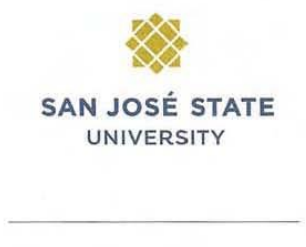

Office of the Provost

Associate Vice President Graduate Studies \& Research

One Washington Square

San José, California 95192-0025

Voice: $408-924-2427$

Fax: 408-924-2612

gradestudies@sjsu.edu

www.sjsu.edu
To: Georgia Toland

From: Pamela Stacks, Ph.D. Associate Vice President Graduate Studies and Research

Date: January 6, 2010

The Human Subjects-Institutional Review Board has registered your study entitled:

"Community College Student Perceptions of Mathematics Instructor Immediacy Behaviors and Associated Perceptions of Cognitive Learning"

This registration, which provides exempt status under Exemption Category 1, of SJSU Policy S08-7, is contingent upon the subjects included in your research project being appropriately protected from risk. This includes the protection of the confidentiality of the subjects when they participate in your research project, and with regard to all data that may be collected from the subjects. The approval includes continued monitoring of your research by the Board to assure that the subjects are being adequately and properly protected from such risks. If at any time a subject becomes injured or complains of injury, you must notify Dr. Pamela Stacks, Ph.D. immediately. Injury includes but is not limited to bodily harm, psychological trauma, and release of potentially damaging personal information. This approval for the human subject's portion of your project is in effect for one year, and data collection beyond January 6, 2011 requires an extension request.

Please also be advised that all subjects need to be fully informed and aware that their participation in your research project is voluntary, and that he or she may withdraw from the project at any time. Further, a subject's participation, refusal to participate, or withdrawal will not affect any services that the subject is receiving or will receive at the institution in which the research is being conducted. If you have any questions, please contact me at (408) 924-2427.

Protocol \#S0904199

cc. Trisha Bergthold

0103 


\section{Appendix D}

\section{Instructor Agreement to Participate in Research}

Responsible Investigator(s): Georgia Toland

Title of Protocol: Community College Student Perceptions of Mathematics Instructor Immediacy

Behaviors and Associated Perceptions of Cognitive Learning

1. You have been asked to participate in a research study investigating community college student perceptions of the verbal and nonverbal behaviors of mathematics teachers and their associated perception of cognitive learning.

2. You will be asked to give a short amount of class time, approximately 15 minutes, to allow the researcher to administer a survey to your students.

3. Risks

- $\quad$ The time it takes to administer the survey will take some class time.

4. Benefits

- Your participation may potentially result in you and other mathematics instructors acquiring a better understanding of communication strategies that work well with community college mathematics students.

5. The results of this study may be published and any information that could identify you will be excluded.

6. Questions about this research may be addressed to Georgia Toland at username@sbcglobal.net. Complaints about the research may be presented to Bradley Jackson, Department Chair, Mathematics Department, at (408) 924-5100. Questions about a research subjects' rights, or research-related injury may be presented to Pamela Stacks, Ph.D., Associate Vice President, Graduate Studies and Research, at (408) 924-2427.

7. No service of any kind, to which you are otherwise entitled, will be lost or jeopardized if you choose not to participate in the study.

8. Your consent is being given voluntarily. You may refuse to participate in the entire study or part of the study. If you decide to participate in the study, you are free to withdraw at any time without any negative effect on your relations with San Jose State University or [the] Community College District.

9. At the time you sign this consent form, you will receive a copy of it for your records, signed and dated by the investigator.

- The signature of a subject on this document indicated agreement to participate in the study.

- The signature of a researcher on this document indicates agreement to include the above named subject in the research and attestation that the subject has been fully informed of his or her rights.

Participant's Signature:

Date:

Investigator's Signature:

Date: 


\section{Appendix E}

\section{Student Agreement to Participate in Research}

Responsible Investigator(s): Georgia Toland

Title of Protocol: Community College Student Perceptions of Mathematics Instructor Immediacy Behaviors and Associated Perceptions of Cognitive Learning

1. You have been asked to participate in a research study investigating community college student perceptions of the verbal and nonverbal behaviors of mathematics teachers and their associated perception of cognitive learning.

2. You will be asked to take a survey that will last approximately 10 minutes.

3. Risks

- The time it takes to administer complete the survey will take some class time.

4. Benefits

- Your participation may potentially result in mathematics instructors acquiring a better understanding of communication strategies that work well with community college mathematics students.

5. The results of this study may be published and any information that could identify you will be excluded.

6. Questions about this research may be addressed to Georgia Toland at username@domain.net. Complaints about the research may be presented to Bradley Jackson, Department Chair, Mathematics Department, at (408) 924-5100. Questions about a research subjects' rights, or research-related injury may be presented to Pamela Stacks, Ph.D., Associate Vice President, Graduate Studies and Research, at (408) 924-2427.

7. No service of any kind, to which you are otherwise entitled, will be lost or jeopardized if you choose not to participate in the study.

8. Your consent is being given voluntarily. You may refuse to participate in the entire study or part of the study. You have the right to not answer questions you do not wish to answer. If you decide to participate in the study, you are free to withdraw at any time without any negative effect on your relations with San Jose State University or [the] Community College District. To withdraw, please return the blank survey form.

9. At the time you sign this consent form, you will receive a copy of it for your records, signed and dated by the investigator.

- The signature of a subject on this document indicated agreement to participate in the study.

- The signature of a researcher on this document indicates agreement to include the above named subject in the research and attestation that the subject has been fully informed of his or her rights.

Participant's Signature:

Date:

Investigator's Signature:

Date: 


\section{Appendix F}

\section{Survey}

Directions: For each behavior listed below, circle how often, if ever, your current mathematics teacher shows the behavior.

\begin{tabular}{|c|c|c|c|c|c|c|}
\hline 1. & Gestures when talking to the class & Never & Rarely & Sometimes & Often & Very Often \\
\hline 2. & Smiles at individual students & Never & Rarely & Sometimes & Often & Very Often \\
\hline 3. & Smiles at the class as a whole & Never & Rarely & Sometimes & Often & Very Often \\
\hline 4. & Makes physical contact with students & Never & Rarely & Sometimes & Often & Very Often \\
\hline 5. & $\begin{array}{l}\text { Moves around the classroom when } \\
\text { teaching }\end{array}$ & Never & Rarely & Sometimes & Often & Very Often \\
\hline 6. & Stands close to students & Never & Rarely & Sometimes & Often & Very Often \\
\hline 7. & Maintains eye contact & Never & Rarely & Sometimes & Often & Very Often \\
\hline 8. & Has tense body & Never & Rarely & Sometimes & Often & Very Often \\
\hline 9. & Looks at the board/notes and not the class & Never & Rarely & Sometimes & Often & Very Often \\
\hline 10. & Stands behind a podium or desk & Never & Rarely & Sometimes & Often & Very Often \\
\hline 11. & Uses personal examples & Never & Rarely & Sometimes & Often & Very Often \\
\hline 12. & Encourages students to talk & Never & Rarely & Sometimes & Often & Very Often \\
\hline 13. & Uses humor & Never & Rarely & Sometimes & Often & Very Often \\
\hline 14. & Uses students' names & Never & Rarely & Sometimes & Often & Very Often \\
\hline 15. & Uses a dull voice & Never & Rarely & Sometimes & Often & Very Often \\
\hline 16. & Praises student work & Never & Rarely & Sometimes & Often & Very Often \\
\hline 17. & Asks about assignments & Never & Rarely & Sometimes & Often & Very Often \\
\hline 18. & Refers to "our" class & Never & Rarely & Sometimes & Often & Very Often \\
\hline 19. & Solicits the viewpoints of students & Never & Rarely & Sometimes & Often & Very Often \\
\hline 20. & Discusses issues unrelated to the class & Never & Rarely & Sometimes & Often & Very Often \\
\hline
\end{tabular}

For this question, think about how much you have learned from your current math teacher.

21 On a scale of 0 to 4, how much have you learned in this $\quad \begin{array}{lllll}0 & 1 & 2 & 3 & 4\end{array}$ math teacher's class? (0 means have learned nothing and 4 means have learned more than in any other math class you've had) 
2.. Think about math teachers in general and indicate on a scale of -2 to 2 how important you think these behaviors are to your learning from a math teacher.

$-2=$ Strong Negative Impact (This behavior significantly hinders my ability to learn mathematics)

$-1=$ Slight Negative Impact

$0=$ No Impact (This behavior does not impact my ability to learn mathematics)

1= Slight Positive Impact

2= Strong Positive Impact (This behavior significantly supports my ability to learn mathematics)

\begin{tabular}{|c|c|c|c|c|c|c|}
\hline 1- & Gestures when talking to the class & -2 & -1 & 0 & 1 & 2 \\
\hline $2-$ & Smiles at individual students & -2 & -1 & 0 & 1 & 2 \\
\hline $3-$ & Smiles at the class as a whole & -2 & -1 & 0 & 1 & 2 \\
\hline 4- & Makes physical contact with students & -2 & -1 & 0 & 1 & 2 \\
\hline $5-$ & Moves around the classroom when teaching & -2 & -1 & 0 & 1 & 2 \\
\hline $6-$ & Stands close to students & -2 & -1 & 0 & 1 & 2 \\
\hline 7- & Maintains eye contact & -2 & -1 & 0 & 1 & 2 \\
\hline $8-$ & Has a relaxed body & -2 & -1 & 0 & 1 & 2 \\
\hline 9- & Looks at the board/notes and not the class & -2 & -1 & 0 & 1 & 2 \\
\hline $10-$ & Stands behind a podium or desk & -2 & -1 & 0 & 1 & 2 \\
\hline 11- & Uses personal examples & -2 & -1 & 0 & 1 & 2 \\
\hline $12-$ & Encourages students to talk & -2 & -1 & 0 & 1 & 2 \\
\hline 13- & Uses humor & -2 & -1 & 0 & 1 & 2 \\
\hline 14- & Uses students' names & -2 & -1 & 0 & 1 & 2 \\
\hline 15- & Has an animated voice & -2 & -1 & 0 & 1 & 2 \\
\hline $16-$ & Praises student work & -2 & -1 & 0 & 1 & 2 \\
\hline 17- & Asks about assignments & -2 & -1 & 0 & 1 & 2 \\
\hline $18-$ & Refers to "our" class & -2 & -1 & 0 & 1 & 2 \\
\hline 19- & Solicits the viewpoints of students & -2 & -1 & 0 & 1 & 2 \\
\hline 20- & Discusses issues unrelated to the class & -2 & -1 & 0 & 1 & 2 \\
\hline
\end{tabular}

23. For this question, think about how much you could learn if you had a math teacher who displayed all of the behaviors that have a positive impact on your learning (items marked 1 or 2 above). On a scale of 0 to 4 , how much do you think you could learn in this hypothetical math teacher's class?

$0=$ No more than in other math classes I've had

$2=$ More than in other math classes I've had

4= Far more than in other math classes I've had

24. Short answer: What is it about those behaviors that you marked as 1 or 2 above that help you to learn mathematics? 


\section{Demographic Information}

1. What is your race? Check all that apply and writein any specifics you feel necessary on the line provided. If more than one race is selected and you identify with one race more than the other(s), please place a star next to the race you most indentify with. $\square$ White (Euro-American/Caucasian)

$\square$ Black/African-American

$\square$ American Indian

$\square$ Mexican/Mexican-American

$\square$ Hispanic, Latino, or Spanish (non-Mexican)

$\square$ Asian (includes Middle East \& Mediterranean)

$\square$ Pacific Islander
2. What is your gender?

Please circle the

3. age range you fall within.
M F
4. Was your teacher of the same race as you?
Yes No Unsure 


\section{Appendix G}

\section{Survey Administration Protocol}

Hi my name is Georgia Toland. I'm a graduate student at San Jose State University and I am here today to request your assistance with my master's thesis research project. I am investigating college students' perceptions of the immediacy behaviors of mathematics instructors and the association with perceived cognitive learning. In other words, I am studying how students like you perceive math teachers' communication styles, verbal and nonverbal, and how that relates to how much you think you learn in a math class. Your participation is completely voluntary. If you choose to participate, you will be asked to fill out a survey that should take no more than 10 minutes to complete. The survey is completely anonymous. Yourself, your instructor, and your school will not be named or recorded and your instructor will not see any of your responses.

The survey asks you to complete a series of questions regarding specific communication behaviors employed by mathematics teachers. Information from this survey will be compiled and used in an effort to determine which behaviors students find to be most beneficial to their mathematics learning. If you do not wish to participate in this survey, you may turn in the blank survey without penalty.

I am going to go ahead and hand out the survey. Please read the Agreement to Participate form on the top of the survey. You will be given two copies of this form. If you wish to participate, sign one of the forms and keep the other for your records. Then 
complete the survey and turn in both the signed Agreement to Participate form and the survey.

Please read the directions at the top of each page and mark your answers clearly using pen or pencil. When you are finished, please place your survey and signed consent form in this folder. Again, if you do not wish to assist with this research, please just return the blank survey and consent form.

Thank you for your time and, hopefully, participation in this project. 


\section{Appendix $\mathbf{H}$}

Description of Demographic Categories

\begin{tabular}{lr}
\hline Category & Racial/Ethnic Background \\
\hline White & European American or Caucasian \\
Black & Black, African American, or African \\
Hispanic & Mexican, Mexican American, Hispanic \\
Asian & Asian, Asian American (including Middle East and Mediterranean) \\
Other & Pacific Islander, American Indian, Multi-racial, or Not Stated \\
\hline
\end{tabular}

